\title{
Alkyne Hydrosilylation Catalyzed by a Cationic Ruthenium Complex: Efficient and General Trans Addition
}

\author{
Barry M. Trost ${ }^{*}$ and Zachary T. Ball \\ Department of Chemistry, Stanford University, Stanford, CA 94305-5080
}

\begin{abstract}
The complex $\left[\mathrm{Cp} * \mathrm{Ru}(\mathrm{MeCN})_{3}\right] \mathrm{PF}_{6}$ is shown to catalyze the hydrosilylation of a wide range of alkynes. Terminal alkynes afford access to $\alpha$-vinylsilane products with good regioselectivity. Deuterium labeling studies indicate a clean trans addition process is at work. The same complex is active in internal alkyne hydrosilylation, where absolute selectivity for the trans addition process is maintained. Several internal alkyne substrate classes, including propargylic alcohols and $\alpha, \beta$-alkynyl carbonyl compounds, allow regioselective vinylsilane formation. The tolerance of a wide range of silanes is noteworthy, including alkyl-, aryl-, alkoxy-, and halosilanes. This advantage is demonstrated in the direct synthesis of triene substrates for silicon-tethered intramolecular DielsAlder cycloadditions.
\end{abstract}

\begin{abstract}
Metal-catalyzed simple addition reactions of alkynes are important synthetic processes and are desirable from the standpoint of synthetic efficiency and atom economy. Questions of regioand stereoselectivity become important considerations, and pathways affording syn addition are plentiful and well studied. Metal catalysis of trans addition processes - where new bonds must be formed on opposite sides of the alkyne - have only rarely been observed. Indeed, the possibility of creating direct trans addition processes which do not involve initial cis addition followed by $E / Z$ isomerization is an exciting target. This paper describes our work studying trans addition processes in alkyne hydrosilylation with ruthenium catalysts to afford vinylsilane products.
\end{abstract}

Vinyl-metal species are extremely important building blocks in organic synthesis. ${ }^{1,2}$ Among these, vinylsilanes play a growing role due to their low cost, low toxicity, ease of handling, and simplicity of byproduct removal. Particularly significant is the potential of vinylsilanes as nucleophilic partners in palladium-catalyzed cross-coupling reactions. ${ }^{3}$ Vinylsilanes are also useful as acceptors in conjugate addition reactions, as masked ketones through Tamao-Fleming oxidation, ${ }^{4}$ and as terminators for cation cyclizations. ${ }^{5}$ Unlike most other organometallic reagents-including in many cases organoboranes and organostannanes_-vinylsilanes can be readily carried through many synthetic operations.

However, the utility of vinylsilanes has been inhibited by the inconvenience of accessing stereo- and regio-defined vinylmetal compounds. Among the possible routes to these compounds, hydrosilylation of alkynes represents the most straightforward, atom-economical access. ${ }^{6}$ Classical platinum catalysis ${ }^{7}$ provides clean cis addition to $(E)$-vinylsilanes (2), and ligand tuning has made this a very regioselective process as well. ${ }^{8}$ In addition, there has been significant progress using a variety of metal-catalyzed approaches to provide stereodefined, 1,2-substituted vinylsilanes of the form $\mathbf{1}$ or $\mathbf{2}$. There has been no reported general access to 
1,1-disubstituted vinylsilanes ${ }^{9}(3)$ and very little is known about selectivity in accessing trisubstituted $(\mathbf{4 , 5})$ vinylsilanes. 10

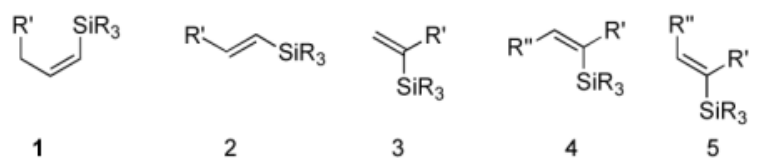

A large number of metal systems are effective in the hydrosilylation of terminal alkynes to produce linear vinylsilanes. Some of these afford good control of olefin geometry. The limited number of known hydrosilylations with ruthenium catalysts give the analogous linear products. 11,12 Free alcohols ${ }^{12}$ and carbonyl groups ${ }^{13}$ have been shown to direct hydrosilylation to provide internal silanes, presumably through coordination. However, at the time this work was conducted and published, ${ }^{14-16}$ there were no reports of non-directed terminal alkyne hydrosilylation to afford preferentially the $\alpha$-vinylsilane (3), ${ }^{17}$ and there remain no alternate hydrosilylation methods to prepare trisubstituted (Z)-vinylsilanes (4).

\section{Reaction discovery, optimization and Markovnikov hydrosilylation of terminal alkynes}

We have for some time pursued a research program targeting the discovery of new simple addition reactions catalyzed by cyclopentadienylruthenium complexes such as $[\mathrm{CpRu}$ $\left.(\mathrm{MeCN})_{3}\right] \mathrm{PF}_{6}(6)$ for the formation of $\mathrm{C}-\mathrm{C}$ and $\mathrm{C}-\mathrm{X}$ bonds. ${ }^{18}$ From this general goal came the discovery that $\left[\mathrm{CpRu}\left(\mathrm{MeCN}_{3}\right] \mathrm{PF}_{6}(\mathbf{6})\right.$ and the related complex $\left[\mathrm{Cp} * \mathrm{Ru}(\mathrm{MeCN})_{3}\right] \mathrm{PF}_{6}(7)$ catalyze the hydrosilylation of alkynes (Table 1). ${ }^{14-16}$

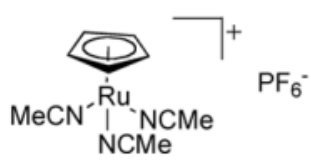

6

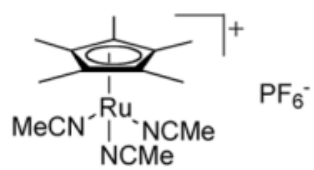

7

Hydrosilylation of terminal alkynes occurs at or below room temperature catalyzed by the ruthenium complex 6 to afford the 1,1-disubstituted, $\alpha$-vinylsilane. This finding is noteworthy as a means of accessing $\alpha$-vinylmetal species in general. Access to $\alpha$-vinylsilanes $12,19,20$ or to other $\alpha$-metalloid species (boron, tin, etc.) in a general and efficient manner is quite limited. 20,21 Complex 6 provides generally excellent results with trialkylsilanes, but regioselectivity is significantly diminished when alkoxysilanes are employed as substrates (Table 1, entry 6). Alkoxysilanes are crucial for many important synthetic applications of vinylsilanes, and poor reactivity or selectivity upon switching to alkoxysilane substrates plagues many extant catalytic systems. In the case at hand, switching to the pentamethylcyclopentadienyl analogue 7 afforded increased selectivity (entry 9). This increased selectivity with complex $\mathbf{7}$ is general. Reaction scope and turnover numbers are very similar for the two catalysts, and so complex $\mathbf{7}$ is the superior catalyst for all reaction classes thus far examined.

A variety of terminal alkynes proved amenable to the reaction, including those with substantial steric bulk (Table 2). The reaction is tolerant to a wide range of functional groups, including halides, alkenes, esters, free alcohols, protected amines, and even free carboxylic acids. Overall, good yields and good regioselectivity are maintained through a wide range of substrates. Limitations of the method include $\alpha$-quaternary centers (entry 11), where we presume that steric demands are too great to allow reactivity, and acyclic 1,6-diynes (entry 12), presumably due to chelation to the metal center. 
In general, terminal alkynes are significantly more reactive than internal alkynes (though electronics and neighboring substitution also play significant roles). This reactivity profile allows for diyne $\mathbf{3 2}$ to react exclusively at the terminal alkyne, even in the presence of a homopropargylic hydroxyl group at the internal alkyne to give vinylsilane $\mathbf{3 3}$ (eq 1).

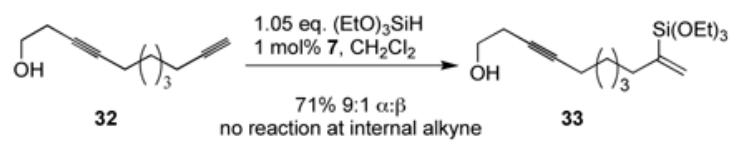

(1).

The use of benzyldimethylsilane (BDMS-H) in alkyne hydrosilylations was deemed especially useful (entries 9-10). The BDMS group of vinylsilane $\mathbf{2 9}$ is activated in under 10 min upon treatment with TBAF in DMF at $0{ }^{\circ} \mathrm{C}$ through protodesilylation of the benzyl group, affording an $\mathrm{Si}-\mathrm{X}$ species, likely the silanol. ${ }^{22}$ This reactive silane intermediate can then be used in situ under mild conditions, such as in palladium-catalyzed cross coupling (Scheme 1). ${ }^{16 a}$

The broad utility of structurally dissimilar silanes is noteworthy in reactions catalyzed by complexes $\mathbf{6}$ and 7. Maintaining selectivity across electronically differentiated silanes is generally difficult. For example, many of the catalysts developed for trans addition to terminal alkynes - forming the $\beta$-vinylsilane - succeed only for alkyl- and arylsilanes, and are poorly selective when synthetically important alkoxysilanes are employed. ${ }^{23,24}$ Solutions to this problem have been rare. ${ }^{25}$ In contrast, we observe exclusively trans addition products and good $\alpha$-selectivity for terminal alkynes with a wide variety of silanes including alkoxy-, trialkyl-, aryl-and benzylic, and even halosilanes (see below). Reaction efficiency and catalyst loading are generally best with trialkylsilanes. Extremely hindered silanes $\left(i-\mathrm{Pr}_{3} \mathrm{SiH}\right)$ fail to react, as does diethylsilane. This last failure is interesting, and may be mechanistically important in light of recent proposals for unique reaction pathways available to dihydridosilanes. 26

Hydrosilylation catalyzed by complex 7 succeeds in a wide variety of solvents. Our initial screen with trialkylsilanes indicated that chlorinated, ethereal, and even homogeneous aqueous mixtures are successful. Only DMF resulted in a particularly poor reaction. Our initial solvent of choice was dichloromethane. However, we became interested in the hydrosilylation of internal alkynes with the rather sluggish benzyldimethylsilane (BDMS-H) for the purposes of

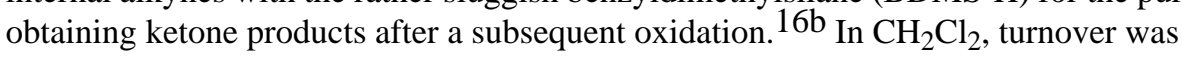
insufficient even in the presence of rather large excesses of silane (Scheme 2, condition a). A brief re-examination of the reaction led to the use of acetone as a solvent, which gave significantly better turnover at lower catalyst loading (condition b). Acetone provides negligible changes in regioselectivity, and it is important to note that although acetone provides better turnover numbers, we do not have reliable data on changes in reaction rate with solvent. The effect is general for all-carbon-substituted silanes, and acetone is the solvent of choice for these silanes. Yields for hydrosilylations with alkoxysilanes-including intramolecular reactions ${ }^{15}$-are significantly reduced in acetone and in protic solvents as a result of extensive decomposition, and so dichloromethane remains the better choice for these reactions. This is presumably due to the difficulty in obtaining truly anhydrous acetone and to the hydrolytic instability of alkoxysilanes in the presence of a Lewis-acidic ruthenium complex.

The stereochemistry of addition is not pertinent with terminal alkynes in cases where $\alpha$-silane formation is predominant, but the observation of a trans addition process with internal alkynes led us to establish the stereochemistry for terminal cases by means of a deuterium labeling experiment. Pleasantly, reaction of the alkyne 8 with triethylsilane- $d$ and complex 7 provided a single product 40 (Scheme 3, eq i). Analysis with ${ }^{1} \mathrm{H}$ NMR indicated $100 \%$ incorporation of deuterium at a single vinyl position resulting from trans addition. ${ }^{27}$ The same experiment with 
rather hindered alkyne $\mathbf{2 6}$ gave the same result (Scheme 3, eq ii). The assignment of trans addition stereochemistry in silane $\mathbf{4 0}$ is based on ${ }^{1} \mathrm{H}$ NMR shifts of related compounds. The cis $(\delta 5.28-5.37)$ and trans $(\delta 5.65-5.75)$ protons relative to silicon of $\alpha$-triethylsilyl vinylsilanes are quite distinct, both for other substrates in this study, and in closely related 1cyclohexenyl-triethylvinylsilane reported elsewhere. ${ }^{28}$ This result indicates that the trans addition phenomenon is general - that it applies to terminal alkynes in addition to internal alkynes. The importance of the result with the sterically demanding terminal alkynes is mechanistically significant. Pathways operating by cis-addition/isomerization mechanisms would be expected to show an erosion in stereochemistry as the steric bulk of the alkyne substituent is increased. Indeed in other reports of clean trans additions to terminal alkynes (to provide ( $Z$ )- $\beta$-vinylsilane products), substantial increases in the steric bulk of the alkyne substituents lead to erosion in $Z / E$ selectivity. This observation was ascribed to the relative similarity of steric bulk between silyl and R groups. ${ }^{23}$ However, we observed no cis-addition products by deuterium incorporation for the quite hindered alkyne $\mathbf{2 6}$ (Scheme 3, eq ii), making it unlikely that the hydrosilylation proceeds through a species such as $\mathbf{4 2}$.

\section{Internal Alkynes}

Many of the most important extant alkyne hydrosilylation catalysts are unreactive toward internal alkynes, and there is a dearth of useful hydrosilylation catalysts for this substrate class. 1,10 We were pleased to find that the same catalyst and conditions which provided regioselective hydrosilylation of terminal alkynes induced clean hydrosilylation of internal alkynes to provide trisubstituted vinylsilanes (Table 3 ). The observed products are exclusively $(Z)$-vinylsilane isomers, the product of a trans addition process. This selectivity has been extremely robust; in extensive examination of a wide range of internal alkynes, we have not observed the formation of any $(E)$-vinylsilanes. ${ }^{29,30}$ This finding is the only reported direct trans addition in the inter molecular hydrosilylation of alkynes. ${ }^{31}$ Functional group tolerance and reaction scope for the reaction is similar to that of terminal alkynes (Table 3). Internal alkynes often produce nearly quantitative yields (>95\%) — higher than those of terminal alkynes-perhaps reflecting that for a terminal alkyne, there exists the possibility for alkynyl $\mathrm{C}-\mathrm{H}$ insertion and/or vinylidene-based side reactions and catalyst decomposition pathways not possible with internal alkynes. ${ }^{32}$

In pursuing regioselectivity with internal alkynes, an initial screen of a few alkynes provided somewhat mixed results (Table 3). Both 1,5- and 1,6-enynes provided very good regioselectivity (entries 1-2). At first, the basis for this selectivity seemed to be coordination of the pendant olefin in some sense, though how the observed regiochemistry fits with a mechanistic picture developed later ${ }^{33}$ is not obvious, and other factors may be at play. In addition, pendant $\mathrm{C}-\mathrm{C}$ unsaturation with the opportunity for chelation to a ruthenium center also results in decreased reactivity, turnover, and yield, and so has not proven to be a general approach to obtaining regiocontrol in the hydrosilylation of internal alkynes.

We also examined simple steric differentiation, which afforded quite selective cis addition in a study by Molander. ${ }^{10}$ Discrimination of a 2 -alkyne provided modest regioselectivity (2.4:1) for the hydrosilylation product with silicon in the less sterically demanding position (Table 3, entry 3). It may be that the selectivity in this case is due more to electronic than to steric considerations. Problems with this approach surfaced when more sterically demanding alkynes were studied in an attempt to improve steric differentiation (entry 4), or when aryl substituents were included (entry 5). In these cases, complete regioselectivity for the hydrosilylation regioisomer with silicon in the more sterically-demanding position was observed. This result is in line with that observed with terminal alkynes. However, low conversion was observed even with quite elevated catalyst loadings. It became apparent that steric differentiation would 
be troublesome if reactivity dropped when sufficient steric bulk was introduced to induce improved regioselectivity. 34

Another possibility is the use of proximal heteroatoms for direction, which has been observed to afford direction in limited cases. ${ }^{12,13}$ Again, the results were initially mixed. The use of a homopropargylic alcohol afforded a 5:1 mixture of regioisomers, with both isomeric siloxanes isolated after intramolecular cyclization onto the pendant alcohol (Table 3, entry 7). However, a $\gamma, \delta$-alkynyl ketone substrate did not demonstrate any direction from the carbonyl group (entry 6). A primary propargylic acetate also afforded rather useful levels of regioselectivity (6:1, entry 8), as did the methyl acetal of 2-butynal (entry 9). The relative contributions of the several factors which could contribute to this selectivity have not been examined. Although initially it is tempting to invoke steric arguments, the strong directing effects later observed with propargylic alcohols indicate that electronic effects are likely important in this case.

\section{Propargylic alcohols}

We became interested in the hydrosilylation of propargylic alcohols. These compounds are readily synthesized in enantiomerically enriched form, 35 and several interesting methodologies based on vinylsilanes bearing allylic alcohols have been developed, despite the circuitous means previously available for accessing such compounds. ${ }^{36}$ Unfortunately, all attempts to perform hydrosilylation of propargylic alcohols with triethoxysilane resulted only in extensive decomposition, and no vinylsilane was ever isolated. This was a surprise, as a terminal alkyne propargylic alcohol could be used as an efficient substrate (see Table 2, entry 4).

Reasoning that poor product stability may be to blame for the observed decomposition, we switched to triethylsilane. This provided an immediate benefit, as the $\beta$-silyl allylic alcohol was formed in quantitative yield and 13:1 regioselectivity (Table 4, entry 2). Again, only the $(Z)$-products of a trans-addition process were observed. Although appropriate for some applications, ${ }^{36 a}$ triethylvinylsilanes are not extensively useful intermediates, and we were interested in a silane with more robust and facile chemistries in further elaboration reactions. The use of monoalkoxy dimethylsilanes did allow isolation of some of the desired silacycle, but the product was so unstable that only very poor yields could be obtained after careful purification on florisil (entry 1). A more bulky secondary alcohol g reatly improved product stability, and the desired vinylsilane was isolated in respectable yield (entry 3 ).

The synthesis of stereodefined polyenoates is often called for in the synthesis of natural product targets. When combined with palladium-catalyzed alkyne-alkyne coupling to produce enyne $\mathbf{7 5}^{37 \mathrm{a}}$ the method described here allows for rapid, atom economical, and catalytic access to dienoate 76 in a stereospecific manner. This route compares favorably to other routes to similar compounds, where obtaining olefin isomer selectivity is often a challenge. $37 \mathrm{~b}$

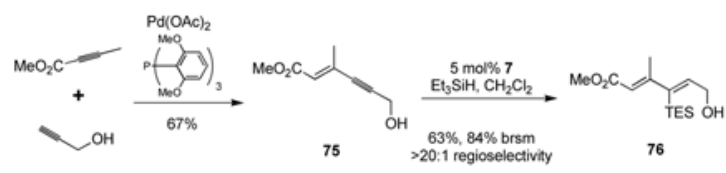

(2).

Although for some subsequent applications the transient formation of the unstable monoalkoxy dimethylsilyl product would suffice, and for some others trialkylvinylsilanes are suitable, we sought a silane that would combine the benefits of both of these silanes. We sought to maintain clean reactivity and good product stability while permitting a wide variety of subsequent operations. After examining several choices, including chlorodimethylsilane and allyldimethylsilane, and considering more exotic choices, in our hands the optimal choice was 
benzyldimethylsilane (BDMS-H), which reacts in a manner similar to triethylsilane, requiring only slightly higher catalyst loadings (generally $2-4 \%$ ). BDMS-H performs well and tolerates a range of functional groups (Table 4). Propargylic alcohol substrates are themselves unique; the presence of neighboring olefins typically produces poor reactivity, but a propargylic hydroxyl allows for significant reactivity (entry8). In addition, propargylic alcohol substrates succeed even in presence of substantial steric bulk. Entry 9 illustrates reactivity with a highly hindered alkyne which proceeds with $3 \%$ catalyst loading (cf. Table 3 , entry 4 , which reacts to only $40 \%$ conversion with $10 \%$ catalyst loading). Indeed, entry 9 undergoes hydrosilylation, whereas 1,3-enynes without propargylic free hydroxyls so far examined fail to react.

\section{$\alpha, \beta$-Alkynyl carbonyl compounds}

The final and probably most robust class of alkynes which we have found amenable to intermolecular hydrosilylation is $\alpha, \beta$-alkynyl carbonyl compounds. The use of catalytic $\left[\mathrm{Cp} * \mathrm{Ru}(\mathrm{MeCN})_{3}\right] \mathrm{PF}_{6}(7)$ in the hydrosilylation of alkynyl esters and ketones provides exclusive trans addition to the $(Z)$-olefin isomer, with very good selectivity for the $\beta$-silyl regioisomer (Table 5). Similar regiochemistry is accessible by stoichiometric silyl-cupration of the alkyne, but the silyl group is generally limited to $\mathrm{SiMe}_{2} \mathrm{Ph}$, the basic silylcuprate prevents tolerance of some functional groups, and direct hydrosilylation is a more atom-economical process. ${ }^{20,38}$ A variety of substituted silanes can be employed. Although $\gamma$-alkoxy groups result in generally lower yields or turnover numbers (entries 6,9), the unprotected $\gamma$-hydroxy compounds are well-tolerated (entries 7,8). An alkynyl acid is also a good substrate for hydrosilylation (entry 10). Interestingly, only 1.2 eq of silane need be employed with the carboxylic acid functionality - a fact demonstrating the chemoselectivity of the rutheniumcatalyzed reaction. Alkoxysilanes are also competent reaction partners (entry 5), but the regioselectivity is somewhat compromised, in line with the trend generally observed for other substrate classes.

The effects of steric demand and electronic perturbations on reactivity result in significant differences in hydrosilylation kinetics among internal alkynes (Scheme 5). As shown, a competition experiment between internal alkynes determined that selective hydrosilylation at an electron-deficient alkynone in the presence of a dialkyl alkyne is possible. Reaction of the ynone substrate is preferred in a 9:1 ratio, as determined by ${ }^{1} \mathrm{H}$ NMR analysis of the crude reaction mixture.

\section{Orthogonal tethers for the Diels-Alder reaction from H-Si-X silanes}

The Diels-Alder reaction constitutes one of the most powerful and widely utilized reactions available to the organic chemist. Highly activated dienes and dienophiles often provide good intermolecular reactivity and regiocontrol. However, relatively unactivated dienes and dienophiles are often quite unreactive, and/or suffer from poor regiocontrol. For this reason, intramolecular Diels-Alder reactions (IMDAs) have been extensively studied as a means of achieving both pre-organization for regio- and stereocontrol, and increased reactivity. Removable tethers allow the advantages of IMDA reactions in cases where bicyclic products are not desired, and silicon tethers are especially useful in this context because they can serve as "traceless" tethers after protodesilylation, or as alcohol surrogates through oxidation.

While disiloxane tethers are one approach, the direct use of vinyl- or dienylsilanes allows increased synthetic efficiency, stability, and potentially selectivity. Very simple vinylsilane tethers are readily synthesized by trapping vinyl organometallic reagents (usually $\mathrm{RMgX}$ or RLi) with dichlorosilanes. ${ }^{40}$ This approach places limits on the functional groups present in the vinylmetallic, and the use of difunctional dichlorosilanes may require large excess of the silyl reagent for smooth monoadditon unless special reagents are employed. ${ }^{40 \mathrm{a}}$ 
Straightforward access to some disubstituted vinylsilanes has been demonstrated. However, more complex substrates such as trisubstituted vinylsilanes are generally only poorly accessible by circuitous means and hence are little investigated — even though they potentially allow access to synthetically challenging products and quaternary stereocenters. ${ }^{41}$ Given the ready access to vinylsilane species provided by ruthenium-catalyzed hydrosilylation, we sought to pursue structures that would be difficult to obtain by other means. We synthesized ${ }^{42}$ the dienyl silane $99\left(\mathrm{HMe}_{2} \mathrm{Si}\right)_{2} \mathrm{NH}, \Delta$; Scheme 6), and found that coupling with a terminal alkyne catalyzed by complex $\mathbf{7}$ did indeed produce the desired triene (Scheme 6). However, the yield was modest, and high loading of ruthenium was required for conversion. The efficiency of obtaining the IMDA substrate (in terms of yield and catalyst loading) could be improved by delaying the diene introduction until after the vinylsilane was formed. A silyl hydride containing a chloride leaving group — such as $\mathrm{HMe}_{2} \mathrm{SiCl}$ — could be used as an orthogonal means of introducing the two tethering units (path b). This should prevent the need for large excesses of the silane as in many traditional tethering protocols where dichlorosilanes are used. The process demonstrates the success of halogenated silanes in hydrosilylation reactions catalyzed by complex $\mathbf{7}$, and should be applicable to building "traceless" tethers for any number of intramolecular reactions.

We were thus excited to find that alkyne 8 reacts with $\mathrm{HMe}_{2} \mathrm{SiCl}$ in the presence of very low levels of complex 7 to provide presumably an intermediate chlorosilane (Scheme 6, path b). This intermediate was not isolated or observed, but rather treated directly with triethylamine and sorbol to give an improved yield of the desired triene in a one-pot process that eliminated the need to isolate and purify a silyl hydride intermediate such as 99. Stork has previously shown that similar 1,1-disubstituted vinylsilanes undergo cycloaddition under thermal conditions. ${ }^{40 \mathrm{a}}$ In a Teflon-sealed screw-cap vial, triene $\mathbf{1 0 0}$ was smoothly converted to bicyclic system 102 at $180{ }^{\circ} \mathrm{C}$ in benzene. (Stork, using a sealed tube, saw reaction of very similar systems at $160{ }^{\circ} \mathrm{C}$. We suspect that the elevated temperatures required for our cycloadditions are due to a lower internal temperature in our apparatus. The same trend is observed for compound 103 below.)

We also turned our attention to a more substituted system. Taking advantage of the good regiocontrol available to $\alpha, \beta$-alkynoates, the one-pot chlorodimethylsilane protocol allowed clean formation of the tethered triene $\mathbf{1 0 3}$. Thermal cycloaddition again provided clean, though sluggish, conversion to what appeared to be the cycloaddition product. Upon exposure to silica, the product decomposed to a mixture of at least two new products. Therefore, we directly treated the crude Diels-Alder adduct 104 with either protodesilylation or oxidation conditions to provide the cyclohexene products $\mathbf{1 0 5}$ and 106, respectively. As discussed earlier, both protodesilylation and silane oxidation are extremely sluggish processes with tertiary silanes. However, a hydroxyl substituent $\beta$ to the silane activates the silane through formation of a 5membered ring silicate. $40 \mathrm{a}, 43$ Oxidation and protodesilylation processes thus proceed at 60 and $80{ }^{\circ} \mathrm{C}$, respectively, to give good yields of the desired cyclohexene products.

The cycloaddition product relative stereochemistry was determined by nOe analysis. The identity of $\mathbf{1 0 2}$ was established from a 1,3-diaxial nOe as shown below. The bold "H" indicates protons with a very small $(<1 \mathrm{~Hz})$ coupling consistent with the perpendicular arrangement of these protons in the cis structure. The alternative trans-102 should have a rather large coupling constant given the nearly co-planar arrangement of the bolded atoms in that structure.

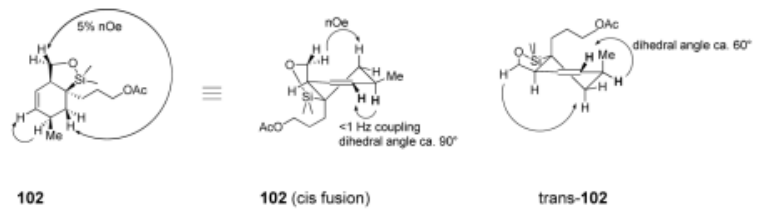


The structure of protodesilylation product $\mathbf{1 0 5}$ could be established through a similar 1,3diaxial nOe. In this case, the large $(10 \mathrm{~Hz})$ coupling constant exhibited by antiperiplanar hydrogen atoms is indicative of the product from an exo-mode Diels-Alder cyclization with respect to the ester substituent.

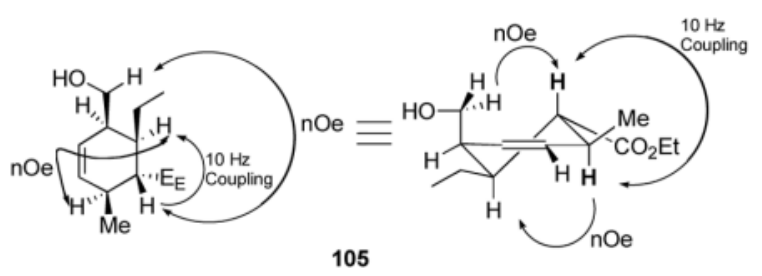

Stereochemical proof of the oxidation product 106 required NOESY analysis, which identifies the exo-adduct through a 1,3-diaxial correlation together with the aforementioned $10.5 \mathrm{~Hz}$ antiperiplanar coupling. 44

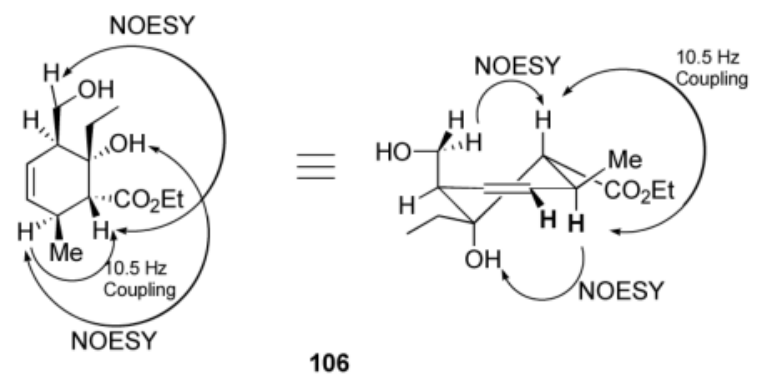

Given the exo-product formation in opposition to that typically expected of intermolecular Diels-Alder reactions, we became interested in determining the basis of the observed selectivity. The endo and exo transition states were located for this reaction, and verified by frequency calculations at the AM1, HF/3-21G(*), and B3LYP/6-31G(d) levels (Figure 1). 4 , 46 All three gave essentially the same result: the exo transition state is favored by 3 to $4 \mathrm{kcal} /$ mol. Specifically, the $\Delta \Delta G^{\ddagger}$ 's for the zero point corrected transition state energies were 3.2 $\mathrm{kcal} / \mathrm{mol}$ [AM1], $4.0 \mathrm{kcal} / \mathrm{mol}$ [HF/3-21G(*)], and $3.7 \mathrm{kcal} / \mathrm{mol}$ [B3LYP/6-31G(d)]. Initial results indicate that the endo-product is 4 to $5 \mathrm{kcal} / \mathrm{mol}$ more stable than the exo; thus the exoproduct is kinetically preferred, but the thermodynamic product is endo- - the opposite of the usual (intermolecular) textbook cases. The transition states themselves are rather different. The disfavored endo-transition state (left) is nearly perfectly synchronous, with incipient bond lengths of $2.19 \AA$ and $2.21 \AA$. The preferred exo transition state is highly asynchronous, however, with incipient bond distances of $2.00 \AA$ and $2.54 \AA$. Although this might suggest that the latter transition state more nearly resembles a Michael addition, there was little evidence of extra charge separation in the calculation.

\section{Conclusion}

The $\mathrm{Cp} * \mathrm{Ru}^{+}$catalyzed hydrosilylation of a wide variety of terminal and internal as well as conjugated and non-conjugated alkynes proceeds rapidly and with good regioselectivity in most cases. In addition, a diverse array of silanes ranging from trialkyl to trialkoxy react. Based upon a qualitative observation of required catalyst loading for complete reaction, a rough order of reactivity can be suggested as $\mathrm{SiEt}_{3} \approx \mathrm{SiMe}_{2} \mathrm{Cl}>\mathrm{SiMe}_{2} \mathrm{OR} \approx \mathrm{Si}(\mathrm{OR})_{3}>\mathrm{SiMe}_{2} \mathrm{Bn} \approx$ $\mathrm{SiMe}_{2} \mathrm{Ph}$. The apparent lower reactivity of the last two, especially $\mathrm{SiMe}_{2} \mathrm{Bn}$ (BDMS), is somewhat surprising given the high reactivity of triethyl silane. The high affinity of this type of ruthenium complex to coordinate with an aromatic ring may account for this apparent anomaly. Nevertheless, the reactions of BDMS-H still proceed in good yields with reasonable 
rates and catalyst loadings. The products of hydrosilylation with this silane are particularly useful for subsequent transformations based upon the fact that the benzyl group is chemoselectively replaced by a hydroxy group with TBAF enabling cross-coupling and Tamao-Fleming oxidations.

The observation of a clean trans addition in each and every case speaks against a mechanism involving an initial cis addition followed by isomerization before the final reductive elimination. This stereochemical course for the Markovnikov hydrosilylation of the two terminal alkynes further attests to this conclusion. A mechanism involving a direct three component addition as depicted in Fig. 2 emerged from calculations. ${ }^{33}$ While it provides a nice rationalization for a direct trans addition, it also provides some enlightenment regarding the regiochemistry. The hypervalency involved in the transition state for $\mathrm{H}$ delivery should favor its delivery to the sterically more accessible alkyne carbon which accounts for the Markovnikov addition with terminal alkynes and several internal alkynes. According to this model, the role of a propargylic alcohol substituent to direct the reaction wherein this substituent resides on $\mathrm{R}^{1}$ is indluctive; an electronegative substituent adjacent to the carbenoid center of the ruthenacyclopropene (i.e. if it were in $\mathrm{R}^{2}$ ) is disfavored. This type of effect also explains the regioselectivity with respect to $\alpha, \beta$-unsaturated carbonyl substrates. The example of Table 4, entry 9 , is quite interesting in this regard. In the competition between a vinylogous carbonyl substituent and a propargylic alcohol, the latter wins although the steric factor may also be a contributor.

The mechanistic hypothesis may illustrate the unique nature in metal catalysts, such as ruthenium, occupying an intermediate place on the periodic table between late transition metals (palladium, rhodium) which exhibit facile oxidation-reduction, and early transition metals and actinides (titanium, thorium) which act through polar mechanisms due to the inaccessibility of oxidation-reduction cycles. In the mechanism proposed here, oxidative addition into the $\mathrm{Si}-\mathrm{H}$ bond is not energetically feasible. Instead, the silane is activated through a $\sigma$-complex in a step reminiscent of early transition metals. The formal oxidation of the ruthenium center certainly can occur, however, to provide the vinylruthenium intermediate. At this point additional stabilization of the ruthenium(IV) center is provided by the $\mathrm{C}-\mathrm{C} \pi$-bond as $\eta^{2}$-coordination of the vinyl ligand.

The use of the hydrosilylation as an entry to the silicon tethered Diels-Alder reaction significantly enhances the utility of this strategy. The exo selectivity provides an additional benefit beyond the regioselectivity compared to the untethered case. Combined with the ability to perform both oxidative desilylation as well as protodesilylation allows for the synthetic equivalent of a $\beta$-hydroxy- $\alpha, \beta$-unsaturated ester dieneophile.

More mechanistic work is clearly called for. Nevertheless, a reasonable case exists that a new mechanistic principle may be involved. From a practical synthetic point of view, the unusual regio- and geometric selectivity adds a new dimension to the atom economic hydrosilylation of alkynes complementary to other catalytic systems and the utility of the resultant vinyl silanes for further structural elaborations.

The complex $\mathbf{7}$ affords the first general access to 1,1-disubstituted vinylsilanes, as well as the first hydrosilylation of internal alkynes by a trans addition pathway. Importantly, a diverse set of silane substituents are compatible with the hydrosilylation reaction, including alkyl, alkoxy, aryl, 2-furanylmethyl, and chloro groups. The regioselectivity combined with the versatility of being able to use almost any type of substituent in silicon bodes well for synthetic applications. For example, the requirement for alkoxyvinylsilanes as partners in rutheniumcatalyzed metathesis ${ }^{47}$ allows the ring forming sequence in Scheme 8 . The resulting cyclic vinylsilanes can then be employed for further elaboration such as Tamao-Fleming oxidation 
and cross coupling. We hope that work presented here spurs the continued development of silicon as a versatile, stable, and environmentally benign vinylmetal species for complex target synthesis. We are intrigued by the prospects that discoveries made in the course of hydrosilylation may portend transition metal-catalyzed trans addition processes with alkynes as a general synthesis of other olefin classes.

\section{Experimental Section}

\section{General procedure for the hydrosilylation of simple alkynes: 5-acetyloxy-2-(triethylsilyl)-1- pentene, 9}

The alkyne $8(50 \mu \mathrm{L}, 0.38 \mathrm{mmol})$, in a flask under Ar was dissolved in $\mathrm{CH}_{2} \mathrm{Cl}_{2}(0.75 \mathrm{~mL}, 0.5 \mathrm{M}$ solution) and treated with triethylsilane $(72 \mu \mathrm{L}, 0.45 \mathrm{mmol})$. The flask was cooled to $0{ }^{\circ} \mathrm{C}$, and solid $6(1.6 \mathrm{mg}, 0.0038 \mathrm{mmol})$ was added at this temperature. The flask was immediately allowed to warm to ambient temperature and stirred for $30 \mathrm{~min}$. The crude reaction mixture was concentrated under reduced pressure and immediately applied to a silica gel column (eluent with 20:1 pet. ether: ether). After purification, $78 \mathrm{mg}$ (86\%) of the desired 1,1-disubstituted silane was isolated as a clear, colorless oil.

$\mathrm{R}_{\mathrm{f}}$ : 0.60 (10:1 pet. ether: EtOAc). ${ }^{1} \mathrm{H}$ NMR $\left(300 \mathrm{MHz}, \mathrm{CDCl}_{3}\right) \delta 5.65(\mathrm{~m}, 1 \mathrm{H}), 5.33(\mathrm{~d}, J=$ $2.7 \mathrm{~Hz}, 1 \mathrm{H}), 4.07(\mathrm{t}, J=6.8 \mathrm{~Hz}, 2 \mathrm{H}), 2.14(\mathrm{t}, J=7.8 \mathrm{~Hz}, 2 \mathrm{H}), 2.05(\mathrm{~s}, 3 \mathrm{H}), 1.75(\mathrm{~m}, 2 \mathrm{H}), 0.93$ $(\mathrm{t}, J=7.8 \mathrm{~Hz}, 9 \mathrm{H}), 0.61(\mathrm{q}, J=7.8 \mathrm{~Hz}, 6 \mathrm{H}) .{ }^{13} \mathrm{C} \mathrm{NMR}\left(75 \mathrm{MHz}, \mathrm{CDCl}_{3}\right) \delta 171.2,147.7,125.6$, 64.2, 32.1, 27.6, 21.0, 7.3, 2.8. IR (thin film) 2955, 2876, 1745 (s), 1239 (s), $720 \mathrm{~cm}^{-1}$. HRMS -EI (m/z): [M] ${ }^{+}$calcd for $\mathrm{C}_{13} \mathrm{H}_{26} \mathrm{O}_{2} \mathrm{Si}: 242.1702$; found: 213.1302 [M-Et].

\section{0-(4-Acetylphenyl)-10-undecenoic acid methyl ester, 35}

Vinylsilane 29 ( $69 \mathrm{mg}, 0.20 \mathrm{mmol}$ ) and 4-iodoacetophenone ( $34 \mu \mathrm{L}, 0.30 \mathrm{mmol})$ were taken up in THF under Ar at $0{ }^{\circ} \mathrm{C}$. TBAF $(0.40 \mathrm{~mL}, 0.40 \mathrm{mmol}, 1.0 \mathrm{M}$ in THF $)$ was then added dropwise, and after $10 \mathrm{~min}$, solid $\mathrm{Pd}_{2} \mathrm{dba}_{3}(4.5 \mathrm{mg}, 0.0050 \mathrm{mmol})$ was added and the flask allowed to warm to rt. After stirring $2 \mathrm{~h}$, the mixture was diluted with ether $(10 \mathrm{~mL})$, and filtered through a plug of silica gel $(\mathrm{ca} .2 \mathrm{~cm})$, washing with additional ether $(20 \mathrm{~mL})$. The filtrate was concentrated under reduced pressure, and the resulting residue applied to a silica gel column (eluent 100:8 pet. ether: EtOAc). to give $56 \mathrm{mg}(89 \%)$ of the desired coupling product as a white crystalline solid.

$\mathrm{R}_{\mathrm{f}}$ : 0.46 (4:1 pet. ether: EtOAc). m.p. $38-39{ }^{\circ} \mathrm{C} .{ }^{1} \mathrm{H} \mathrm{NMR}\left(300 \mathrm{MHz}, \mathrm{CDCl}_{3}\right) \delta 7.93(\mathrm{~d}, J=$ $8.5 \mathrm{~Hz}, 2 \mathrm{H}), 7.48(\mathrm{~d}, J=8.5 \mathrm{~Hz}, 2 \mathrm{H}), 5.35(\mathrm{~d}, J=1.0 \mathrm{~Hz}, 1 \mathrm{H}), 5.16(\mathrm{~d}, J=1.0 \mathrm{~Hz}, 1 \mathrm{H}), 3.66$ $(\mathrm{s}, 3 \mathrm{H}), 2.60(\mathrm{~s}, 3 \mathrm{H}), 2.51(\mathrm{t}, J=7.3 \mathrm{~Hz}, 2 \mathrm{H}), 2.29(\mathrm{~d}, J=7.5 \mathrm{~Hz}, 2 \mathrm{H}), 1.60(\mathrm{~m}, 2 \mathrm{H}), 1.43(\mathrm{~m}$, 2H), 1.22-1.34 (m, 8H). ${ }^{13} \mathrm{C}$ NMR $\left(75 \mathrm{MHz}, \mathrm{CDCl}_{3}\right) \delta 197.7,174.3,147.8,146.2,135.9$, 128.4, 126.2, 114.1, 51.4, 35.1, 34.0, 29.1 (2C), 29.0 (2C), 28.1, 26.6, 24.9. IR (thin film) 2930, 2856, 1739 (s), 1683 (s), 1604, 1268, $847 \mathrm{~cm}^{-1}$. Anal. Calc. for $\mathrm{C}_{20} \mathrm{H}_{28} \mathrm{O}_{3}: \mathrm{C}, 75.91 ; \mathrm{H}, 8.92$. Found: C, 76.12; H, 9.06 .

\section{(2R,3S)-1,2,3-trihydroxy-5-undecanone 1,2-isopropylidene ketal, 38}

The alkyne $36(120 \mathrm{mg}, 0.50 \mathrm{mmol})$ and BDMS-H (104 $\mu \mathrm{L}, 0.60 \mathrm{mmol})$ in acetone $(1.0 \mathrm{~mL})$ was treated at $0{ }^{\circ} \mathrm{C}$ with complex $7(7.8 \mathrm{mg}, 0.015 \mathrm{mmol}$; the mixture was allowed to warm to rt over $30 \mathrm{~min}$. It was then re-cooled to $0^{\circ} \mathrm{C}$, diluted with THF $(1.5 \mathrm{~mL})$, and TBAF $(0.60 \mathrm{~mL}$, $0.60 \mathrm{mmol}, 1.0 \mathrm{M}$ soln in THF) was added dropwise. After $20 \mathrm{~min}, \mathrm{MeOH}(1.0 \mathrm{~mL})$ was introduced, followed by solid potassium bicarbonate $(150 \mathrm{mg}, 1.5 \mathrm{mmol})$ and aq. $\mathrm{H}_{2} \mathrm{O}_{2}$. $(0.80$ $\mathrm{mL}, 30 \%$ soln). The mixture was then stirred for $36 \mathrm{~h}$ at $\mathrm{rt}$, at which time it was diluted with water $(10 \mathrm{~mL})$ and extracted with EtOAc $(3 \times 10 \mathrm{~mL})$. The organic extracts were washed with brine $(10 \mathrm{~mL})$, dried over $\mathrm{Na}_{2} \mathrm{SO}_{4}$, and concentrated in vacuo. The residue was purified on a 
silica gel column (eluent: 85:15:1 pet. ether: EtOAc: $\mathrm{MeOH}$ ) to give $99 \mathrm{mg}(77 \%)$ of the desired ketone as a single isomeric compound.

${ }^{1} \mathrm{H}$ NMR $\left(500 \mathrm{MHz}, \mathrm{CDCl}_{3}\right) \delta 4.08(\mathrm{~m}, 1 \mathrm{H}), 3.92-3.95(\mathrm{~m}, 3 \mathrm{H}), 3.27(\mathrm{br} \mathrm{OH}, 1 \mathrm{H}), 2.82(\mathrm{dd}$, $J=7.5,1.8 \mathrm{~Hz}, 1 \mathrm{H}), 2.57(\mathrm{~m}, 1 \mathrm{H}), 2.45(\mathrm{t}, J=7.5 \mathrm{~Hz}, 2 \mathrm{H}), 1.57(\mathrm{~m}, 2 \mathrm{H}), 1.39(\mathrm{~s}, 3 \mathrm{H}), 1.34$ (s, 3H), $1.26-1.30(\mathrm{~m}, 6 \mathrm{H}), 0.87(\mathrm{t}, J=7.0 \mathrm{~Hz}, 3 \mathrm{H}) .{ }^{13} \mathrm{C} \mathrm{NMR}\left(125 \mathrm{MHz}, \mathrm{CDCl}_{3}\right) \delta 212.4$, $109.4,77.5,69.1,66.9,45.1,43.7,31.5,28.8,26.7,25.1,23.5,23.5,22.4,14.0$. IR (thin film) 3472 (br, OH), 2932 (s), 1713, 1372, 1215, 1066 (s), $851(\mathrm{w}) \mathrm{cm}^{-1}$. $[\alpha]^{26}{ }_{\mathrm{D}}-21.3^{\circ}$ (c 1.3, $\mathrm{CHCl}_{3}$ ). Anal. calc. for $\mathrm{C}_{14} \mathrm{H}_{26} \mathrm{O}_{4}: \mathrm{C}, 65.09 ; \mathrm{H}, 10.14$; Found: C, 64.84; H, 9.92 .

\section{(士)-(S,S)-4-(benzyldimethylsilyl)-7-(4-methoxy-benzyloxy)-1-phenyl-undec-4-en-6-ol, 70}

To a solution of ( \pm )-(S,S)-7-(4-methoxy-benzyloxy)-1-phenyl-undec-4-yn-6-ol (50 mg, 0.13 $\mathrm{mmol}$ ) and benzyldimethylsilane $(23.7 \mathrm{mg}, 0.16 \mathrm{mmol})$ in $\mathrm{CH}_{2} \mathrm{Cl}_{2}(0.26 \mathrm{~mL}$ ) is added [Cp* $\mathrm{Ru}$ $\left.(\mathrm{MeCN})_{3}\right] \mathrm{PF}_{6}(7)(3.3 \mathrm{mg}, 0.0065 \mathrm{mmol})$ at $0{ }^{\circ} \mathrm{C}$. The solution is allowed to warm to $\mathrm{rt}$ and stirred for $20 \mathrm{~min}$, at which time TLC analysis indicated incomplete consumption of the alkyne. Another portion of complex 7 ( $3.3 \mathrm{mg}, 0.0065 \mathrm{mmol}$ ) is added, the solution is stirred for 20 min, filtered through a plug of florisil, concentrated under reduced pressure and yielded $( \pm)$ (S,S)-4-(benzyl-dimethyl-silanyl)-7-(4-methoxy-benzyloxy)-1-phenyl-undec-4-en-6-ol (53.6 $\mathrm{mg}, 78 \%$ ) after purification on a silica gel column (eluent: 6:1, then 4:1 pet. ether: ether).

$\mathrm{R}_{\mathrm{f}}$ : 0.16 (4:1 pet. ether: ether). ${ }^{1} \mathrm{H}$ NMR $\left(300 \mathrm{MHz}, \mathrm{CDCl}_{3}\right) \delta 6.85-7.23(\mathrm{~m}, 14 \mathrm{H}), 6.00(\mathrm{~d}, J$ $=9.5,1 \mathrm{H}), 4.45-4.62(\mathrm{~m}, 2 \mathrm{H}), 4.11-4.17(\mathrm{~m}, 1 \mathrm{H}), 3.87(\mathrm{~s}, 3 \mathrm{H}), 3.12-3.25(\mathrm{~m}, 1 \mathrm{H}), 2.57(\mathrm{t}, J$ $=8.1,2 \mathrm{H}), 2.39(\mathrm{~d}, J=3.2,1 \mathrm{H}), 2.01-2.27(\mathrm{~m}, 4 \mathrm{H}), 1.26-1.67(\mathrm{~m}, 8 \mathrm{H}), 0.89(\mathrm{t}, J=6.8,3 \mathrm{H})$, $0.08-0.12(\mathrm{~m}, 6 \mathrm{H}) .{ }^{13} \mathrm{C}$ NMR $\left(125 \mathrm{MHz}, \mathrm{CDCl}_{3}\right) \delta 159.7,144.5,142.6,141.9,140.0,130.6$, 129.9, 128.7, 128.61, 128.57, 128.42, 126.0, 124.5, 114.2, 83.2, 73.1, 72.7, 55.6, 38.2, 36.1, $32.3,31.3,28.2,26.9,23.2,14.3,-1.1,-1.4$. IR (thin film) 3585 (br), 2931, 2361, 1612, 1514, 1249 (s), 1035, 828, $699 \mathrm{~cm}^{-1}$. Anal. Calc. for $\mathrm{C}_{34} \mathrm{H}_{46} \mathrm{O}_{3} \mathrm{Si}: \mathrm{C}, 76.93 ; \mathrm{H}, 8.73$. Found: C, 77.04; $\mathrm{H}, 8.83$.

\section{General procedure for ruthenium-catalyzed hydrosilylation of a,b-alkynyl carbonyl compounds: (Z)-5-(Benzyldimethylsilyl)-4-hepten-3-one, 78}

Neat 4-hepyn-3-one ( $4.14 \mathrm{~g}, 37.6 \mathrm{mmol})$ and benzyldimethylsilane $(7.79 \mathrm{~mL}, 45.1 \mathrm{mmol})$ were taken up in acetone $(60 \mathrm{~mL})$ at $0{ }^{\circ} \mathrm{C}$ under Ar. Solid $\left[\mathrm{Cp} * \mathrm{Ru}(\mathrm{MeCN})_{3}\right] \mathrm{PF}_{6}(95 \mathrm{mg}, 0.188 \mathrm{mmol})$ was added, and the ice bath removed to allow the solution to reach rt. After $30 \mathrm{~min}$, the acetone was removed under reduced pressure and the resulting residue applied directly to a silica gel plug (ca. $6 \mathrm{~cm}$, eluent 40:1 pet. ether: ether) to provide the desired ( $Z$ )-vinylsilane $(9.61 \mathrm{~g}, 98 \%)$ as a clear, colorless oil.

${ }^{1} \mathrm{H}$ NMR (300 MHz, $\mathrm{CDCl}_{3}$ ) d 6.98-7.22 (m, 5H), $6.68(\mathrm{t}, J=1.4 \mathrm{~Hz}, 1 \mathrm{H}), 2.55(\mathrm{q}, J=7.2$ $\mathrm{Hz}, 2 \mathrm{H}), 2.37(\mathrm{~s}, 2 \mathrm{H}), 2.15(\mathrm{qd}, J=7.3,1.5 \mathrm{~Hz}, 2 \mathrm{H}), 1.13(\mathrm{t}, J=7.3 \mathrm{~Hz}, 1 \mathrm{H}), 0.89(\mathrm{t}, J=7.3$ $\mathrm{Hz}, 1 \mathrm{H}), 0.10(\mathrm{~s}, 6 \mathrm{H}) .{ }^{13} \mathrm{C}$ NMR $\left(75 \mathrm{MHz}, \mathrm{CDCl}_{3}\right) \mathrm{d} 165.4,140.6,136.4,128.4,128.1,127.9$, 123.8, 36.5, 31.6, 24.8, 13.6, 8.1, -2.3. IR (thin film) 2969, 1690 (s), 1576, 1493, 1246, 1143, $828,699 \mathrm{~cm}^{-1}$. Additional characterization is provided elsewhere after additional synthetic operations.

\section{(2Z,2'E,4'E)-3-(Hexa-2,4-dienyloxydimethysilyl)-2-pentenoic acid ethyl ester, 103}

Ethyl 2-pentynoate $(200 \mu \mathrm{L}, 1.52 \mathrm{mmol})$ under $\mathrm{Ar}$ at $0{ }^{\circ} \mathrm{C}$ was taken up in $\mathrm{CH}_{2} \mathrm{Cl}_{2}(3 \mathrm{~mL})$. Dimethylchlorosilane ( $202 \mu \mathrm{L}, 1.82 \mathrm{mmol}$, freshly dist. from $\mathrm{CaH}_{2}$ ) was added, followed by solid complex 7 (7.0 mg, $0.015 \mathrm{mmol})$. The flask was allowed to warm to rt and was stirred for $30 \mathrm{~min}$. The flask was then re-cooled to $0{ }^{\circ} \mathrm{C}$ and was treated sequentially with triethylamine $(423 \mu \mathrm{L}, 3.03 \mathrm{mmol})$ and $(E, E)$-hexadien-1-ol (sorbol) $(290 \mu \mathrm{L}, 2.58 \mathrm{mmol})$. Additional $\mathrm{CH}_{2} \mathrm{Cl}_{2}(3 \mathrm{~mL})$ was added to ensure solubility, and the flask was warmed to $\mathrm{rt}$ and stirred for 
$30 \mathrm{~min}$. The mixture was diluted with benzene $(15 \mathrm{~mL})$ and filtered through celite, washing with additional benzene $(15 \mathrm{~mL})$. The filtrate was concentrated under reduced pressure and purified by silica gel chromatography (eluent: $20: 1$ pet. ether : ether) to afford $371 \mathrm{mg}(87 \%)$ of the desired silyl ether as a clear, colorless oil.

$\mathrm{R}_{\mathrm{f}}$ : 0.26 (4:1 pet. ether: ether). ${ }^{1} \mathrm{H}$ NMR $\left(300 \mathrm{MHz}, \mathrm{CDCl}_{3}\right)$ d $7.25(\mathrm{dd}, J=8.0,8.0 \mathrm{~Hz}, 1 \mathrm{H})$, $6.99(\mathrm{~d}, J=7.2 \mathrm{~Hz}, 1 \mathrm{H}), 6.93(\mathrm{~s}, 1 \mathrm{H}), 6.82(\mathrm{dd}, J=8.0,2.4 \mathrm{~Hz}, 1 \mathrm{H}), 5.30(\mathrm{~s}, 1 \mathrm{H}), 5.08(\mathrm{~s}, 1 \mathrm{H})$, $4.08(\mathrm{t}, J=7.0 \mathrm{~Hz}, 2 \mathrm{H}), 3.82(\mathrm{~s}, 3 \mathrm{H}), 2.56(\mathrm{t}, J=7.0 \mathrm{~Hz}, 2 \mathrm{H}), 2.05(\mathrm{~s}, 3 \mathrm{H}), 1.79(\mathrm{tt}, J=7.0$, $7.0 \mathrm{~Hz}, 2 \mathrm{H}) .{ }^{13} \mathrm{C}$ NMR $\left(75 \mathrm{MHz}, \mathrm{CDCl}_{3}\right) \mathrm{d} 171.1,159.5,147.1,142.3,129.2,118.6,113.0$, 112.5, 112.1, 63.9, 55.2, 31.7, 27.1, 21.0. IR (thin film) 2956, 1739 (s), 1577, 1240 (s), 1041 $\mathrm{cm}^{-1}$. Further characterization after formation of $\mathbf{1 1 4}$.

\section{(1R,2S,5R,6R)-6-Ethyl-5-hydroxymethyl-2-methyl-cyclohex-3-enecarboxylic acid ethyl ester, 105}

The starting triene $(102 \mathrm{mg}, 0.361 \mathrm{mmol})$ was taken up in benzene- $d_{6}(4 \mathrm{~mL})$ in a teflon-ringed screw-top vial and placed in a $180^{\circ} \mathrm{C}$ bath for $20 \mathrm{~h}$. The solution was then transferred to a round-bottomed flask and the solvent removed under reduced pressure. The residue was taken up in DMF $(1.5 \mathrm{~mL})$ and treated with TBAF $(1.5 \mathrm{~mL}, 1.50 \mathrm{mmol}, 1.0 \mathrm{M}$ in THF). The solution was brought to $75^{\circ} \mathrm{C}$ and stirred for $4 \mathrm{~h}$. The mixture was cooled to rt and sat. aq $\mathrm{NaHCO}_{3}(15$ $\mathrm{mL})$ and water $(15 \mathrm{~mL})$ were added and the mixture was extracted with EtOAc $(2 \times 15 \mathrm{~mL})$. The combined extracts were washed with brine $(10 \mathrm{~mL})$, dried over $\mathrm{Na}_{2} \mathrm{SO}_{4}$, and concentrated under reduced pressure. Chromatography on silica gel (eluent 10:1 pet. ether : ethyl acetate) provided the desired alcohol $(56.5 \mathrm{mg}, 69 \%)$ as a pale yellow oil.

$\mathrm{R}_{\mathrm{f}}$ : 0.65 (1:1 pet. ether : EtOAc). ${ }^{1} \mathrm{H}$ NMR $\left(500 \mathrm{MHz}, \mathrm{CDCl}_{3}\right.$ ) d 5.75 (s, 2H), 4.19 (qd, J=7.1, $1.0 \mathrm{~Hz}, 2 \mathrm{H}), 3.72-3.82(\mathrm{~m}, 2 \mathrm{H}), 2.52(\mathrm{~m}, 1 \mathrm{H}), 2.44(\mathrm{~m}, 1 \mathrm{H}), 2.31(\mathrm{dd}, J=11.4,10.0 \mathrm{~Hz}, 1 \mathrm{H})$, $1.91(\mathrm{~m}, 1 \mathrm{H}), 1.33-1.45(\mathrm{~m}, 2 \mathrm{H}), 1.30(\mathrm{t}, J=7.1 \mathrm{~Hz}, 3 \mathrm{H}), 0.99(\mathrm{~d}, J=7.0 \mathrm{~Hz}, 3 \mathrm{H}), 0.94(\mathrm{t}, J$ $=7.4 \mathrm{~Hz}, 3 \mathrm{H}) .{ }^{13} \mathrm{C} \mathrm{NMR}\left(125 \mathrm{MHz}, \mathrm{CDCl}_{3}\right) \mathrm{d} 176.4,134.9,126.4,62.0,60.1,51.4,40.2,37.1$, 34.9, 22.8, 20.1, 14.4, 11.5. IR (thin film) 3444 (br, OH), 2962, 2877, 1731, 1458, 1375, 1177, $1035 \mathrm{~cm}^{-1}$. Anal. calc. for $\mathrm{C}_{13} \mathrm{H}_{22} \mathrm{O}_{3}$ : C, 68.99; H, 9.80; Found: C, 69.13; H, 9.59. HRMS$\mathrm{EI}(\mathrm{m} / \mathrm{z}):[\mathrm{M}]^{+}$calcd for $\mathrm{C}_{13} \mathrm{H}_{22} \mathrm{O}_{3}: 226.1569$; found: 226.1566 .

\section{Supplementary Material}

Refer to Web version on PubMed Central for supplementary material.

\section{Acknowledgements}

The authors thank Prof. Robert Pascal for performing calculations on the Diels-Alder transition state leading to compound 104 and Thomas Jöge for important initial experiments. We acknowledge the National Science Foundation and the National Institutes of Health (GM13598) for their generous support of our programs Z.T.B. received support from an Althouse Family Stanford Graduate Fellowship. Mass spectra were provided by the Mass Spectrometry Facility, University of San Francisco, supported by the NIH Division of Research Resources.

\section{References}

1. Ojima, I.; Li, Z.; Zhu, J. The Chemistry of Organosilicon Compounds. Rappoport, Z.; Apeloig, Y., editors. 2. John Wiley \& Sons; Great Britain: 1998. p. 1687-1792.

2. Langkopf E, Schinzer D. Chem Rev 1995;95:1375-1408.

3. Hatanaka Y, Hiyama T. Synlett 1991:845-853.Hiyama, T. Metal-catalyzed Cross-coupling Reactions. Diederich, F.; Stang, P., editors. Wiley-VCH; Weinheim: 1998. Mowery M, DeShong P. Org Lett 1999;1:2137-2140. [PubMed: 10836067]Denmark SE, Sweis RF. Acc Chem Res 2002;35:835-846. [PubMed: 12379136] 
4. Tamao K, Maeda K. Tetrahedron Lett 1986;27:65-68.Jones GR, Landais Y. Tetrahedron 1996;52:7599-7662.

5. Blumenkopf TA, Overman LE. Chem Rev 1986;86:857-873.

6. Hiyama, T.; Kusumoto, T. Comprehensive Organic Synthesis. Trost, BM.; Fleming, I., editors. 8. Pergamon; Oxford: 1991. p. 763-792.Trost, BM.; Ball, ZT. Synthesis. 2005. in press

7. Lewis LN, Sy KG, Bryant GL, Donahue PE. Organometallics 1991;10:3750-3759.Voronkov MG, Pukhnarevich VB, Tsykhanskaya II, Ushakova NI, Gaft YL, Zakharova IA. Inorg Chim Acta 1983;68:103-105.

8. Green M, Spencer JL, Stone FGA, Tsipis CA. J Chem Soc, Dalton Trans 1977:1525-1529.Tsipis CA. J Organomet Chem 1980;187:427-446.Takahashi K, Minami T, Ohara Y, Hiyama T. Tetrahedron Lett 1993;34:8263-8266.Denmark SE, Wang ZG. Org Lett 2001;3:1073-1076. [PubMed: 11277798]

9. For an approach see Sharma S, Oehlschlager AC. Tetrahedron Lett 1988;29:261-264.

10. Molander GA, Retsch WH. Organometallics 1995;14:4570-4575.

11. Esteruelas MA, Herrero J, Oro LA. Organometallics 1993;12:2377-2379.

12. Na Y, Chang S. Org Lett 2000;2:1887-1889. [PubMed: 10891183]

13. Murai T, Kimura F, Tsutsui K, Hasegawa K, Kato S. Organometallics 1998;17:926-932.

14. (a) Trost BM, Ball ZT. J Am Chem Soc 2001;123:12726-12727. [PubMed: 11741457] (b) Trost BM, Ball ZT, Joege T. J Am Chem Soc 2002;124:7922-7923. [PubMed: 12095335] (c) Trost BM, Ball ZT. J Am Chem Soc 2004;126:13942-13944. [PubMed: 15506753]

15. Trost BM, Ball ZT. J Am Chem Soc 2003;125:30-31. [PubMed: 12515496]

16. (a) Trost BM, Machacek MR, Ball ZT. Org Lett 2003;5:1895-1898. [PubMed: 12762680] (b) Trost BM, Ball ZT, Jöge T. Angew Chem, Int Ed Engl 2003;42:3415-3418. [PubMed: 12888974]

18. Kawanami Y, Sonade Y, Mori T, Yamamoto K. Org Lett 2002;4:2825-2827. [PubMed: 12182565]

17. Trost BM, Pinkerton AB. Angew Chem, Int Ed Engl 2000;39:360-362. [PubMed: 10649409]Trost BM, Pinkerton AB. J Am Chem Soc 1999;121:1988-1989.Trost BM, Fraisse PL, Ball ZT. Angew Chem, Int Ed Engl 2002;41:1059-1061. [PubMed: 12491312]

19. Fleming I, Newton TW, Roessler F. J Chem Soc, Perkin Trans 1 1981:2527-2532.

20. Betzer JF, Pancrazi A. Synlett 1998:1129.

21. Betzer JF, Delaloge F, Muller B, Pancrazi A, Prunet J. J Org Chem 1997;62:7768-7780.Stoltz BM, Kano T, Corey EJ. J Am Chem Soc 2000;122:9044-9045.Kazmaier U, Schauss D, Pohlman M. Org Lett 1999;1:1017-1019.Kazmaier U, Pohlman M, Schauss D. Eur J Org Chem 2000:2761-2766.

22. Denmark S, Wehrli D, Choi J. Org Lett 2000;2:2491-2494. [PubMed: 10956529]

23. Jun CH, Crabtree RH. J Organomet Chem 1993;447:177-187.Ojima I, Clos N, Donovan RJ, Ingallina P. Organometallics 1990;9:3127-3133.

24. Tanke RS, Crabtree RH. Organometallics 1991;10:415-418.Tanke RS, Crabtree RH. J Am Chem Soc 1990;112:7984-7989.Esteruelas MA, Nurnberg O, Olivan M, Oro LA, Werner H. Organometallics 1993;12:3264-3272.Ojima I, Kumagai M, Nagai Y. J Organomet Chem 1974;66:C14-C16.

25. Faller JW, D'Alliessi DG. Organometallics 2002;21:1743-1746.

26. Glaser PB, Tilley TD. J Am Chem Soc 2003;125:13640-13641. [PubMed: 14599184]

27. Notably, a single experiment repeating these results with complex 6 appears to contain $15-20 \%{ }^{1} \mathrm{H}$ at the trans addition position. We have not ruled whether H-D exchange with the terminal alkyne prior to hydrosilylation is to blame for this anomaly, though it is possible that under some conditions a cis addition might be a minor, competing pathway.

28. Kang SK, Hong YT, Lee JH, Kim WY, Lee I, Yu CM. Org Lett 2003;5:2813-2816. [PubMed: 12889881]Fuerstner A, Kollegger G, Weidmann H. J Organomet Chem 1991;414:295-305.

29. Small amounts (ca. 5\%) of the (E)-vinylsilanes have been reported by Fürstner in the hydrosilylation of rather small macrocyclic alkynes (12-14 members) with complex 7. Larger rings resulted in only (Z)-vinylsilane products. See reference 30.

30. Fürstner A, Radkowski K. Chem Commun 2002:2182-2183.Lacombe F, Radkowski K, Seidel G, Fürstner A. Tetrahedron 2004;60:7315-7324.

31. Denmark SE, Pan W. Org Lett 2003;5:1119-1122. [PubMed: 12659588] 
32. Trost BM, Rhee YH. J Am Chem Soc 2003;125:7482-7483. [PubMed: 12812465]Trost BM, Rhee YH. J Am Chem Soc 2002;124:2528-2533. [PubMed: 11890802]

33. Chung LW, Wu YD, Trost BM, Ball ZT. J Am Chem Soc 2003;125:11578-11582. [PubMed: 13129361]

34. Reactivity in a trans addition process can be achieved for such hindered substrates with intramolecular hydrosilylation reactions. See ref. 15.

35. Ojima, I., editor. Catalytic Asymmetric Synthesis. 2. Wiley-VCH; New York: 2000. Frantz DE, Fassler R, Carreira EM. J Am Chem Soc 2000;122:1806-1807.Anand NK, Carreira EM. J Am Chem Soc 2001;123:9687-9688. [PubMed: 11572696]Boyall D, Frantz DE, Carreira EM. Org Lett 2002;4:2605-2606. [PubMed: 12123387]

36. Hasan I, Kishi Y. Tetrahedron Lett 1980;21:4229-4232. (b) Taguchi H, Ghoroku K, Tadaki M, Tsubouchi A, Takeda T. Org Lett 2001;3:3811-3814. [PubMed: 11700145]

37. (a) Trost BM, Sorum MT, Chan C, Harms AE, Ruhter G. J Am Chem Soc 1997;119:698-708. (b) Smith AB, Walsh SP, Frohn M, Duffey MO. Org Lett 2005;7:139-142. [PubMed: 15624997]

38. Fleming I, Newton TW, Sabin V, Zammattio F. Tetrahedron 1992;48:7793-7802.

39. Bols M, Skrydstrup T. Chem Rev 1995;95:1253.Fensterbank L, Malacria M, Sieburth S. Synthesis 1997:813.Gauthier DR Jr, Zandi KS, Shea KJ. Tetrahedron 1998;54:229.

40. (a) Stork G, Chan TY, Breault GA. J Am Chem Soc 1992;114:7578-7579. (b) Brosius AD, Overman LE, Schwink L. J Am Chem Soc 1999;121:700-709. (c) Shea KJ, Zandi KS, Staab AJ, Carr R. Tetrahedron Lett 1990;31:5885-5888. (d) Gauthier DR Jr, Zandi KS, Shea KJ. Tetrahedron 1998;54:2289-2338.

41. Tamao K, Kobayashi K, Ito Y. J Am Chem Soc 1989;111:6478-6480.

42. Marshall JA, Yanik MM. Org Lett 2000;2:2173-2175. [PubMed: 10891259]

43. Stork G, Chan TY. J Am Chem Soc 1995;117:6595-6596.

44. The exo adduct is more in line with NMR data at hand than the endo product previously proposed for a similar (less substituted) case. See reference 40a.

45. All calculations were performed by using GAUSSIAN 98. The built-in default thresholds for wave function and gradient convergence were employed, transition states were located by using the QST3 option, and they were verified by analytical frequency calculations.

46. Frisch, MJ., et al. Gaussian, Inc; Pittsburgh, PA: 1998.

47. Chatterjee AK, Morgan JP, Scholl M, Grubbs RH. J Am Chem Soc 2000;122:3783-3784.Pietraszuk C, Marciniec B, Fischer H. Organometallics 2000:913.Denmark SE, Yang SM. Org Lett 2001;3:1749. [PubMed: 11405702] 
<smiles>C/C=C\C=C\CO[Si](C)(C)/C(C)=C/C(=O)OCC</smiles>

endo-104 model<smiles>COC(=O)[C@H]1[C@@H](C)C=C[C@@H]2CO[Si](C)(C)[C@]21C</smiles>

exo-104 model

transition state $\left(\Delta \Delta G^{\ddagger}\right)$

ground state $(\Delta \mathrm{G})$

$$
\begin{array}{cc}
+3.6 & 0.0 \\
0.0 & +4.5 \\
\text { relative energies } & (\mathrm{kcal} / \mathrm{mol})
\end{array}
$$
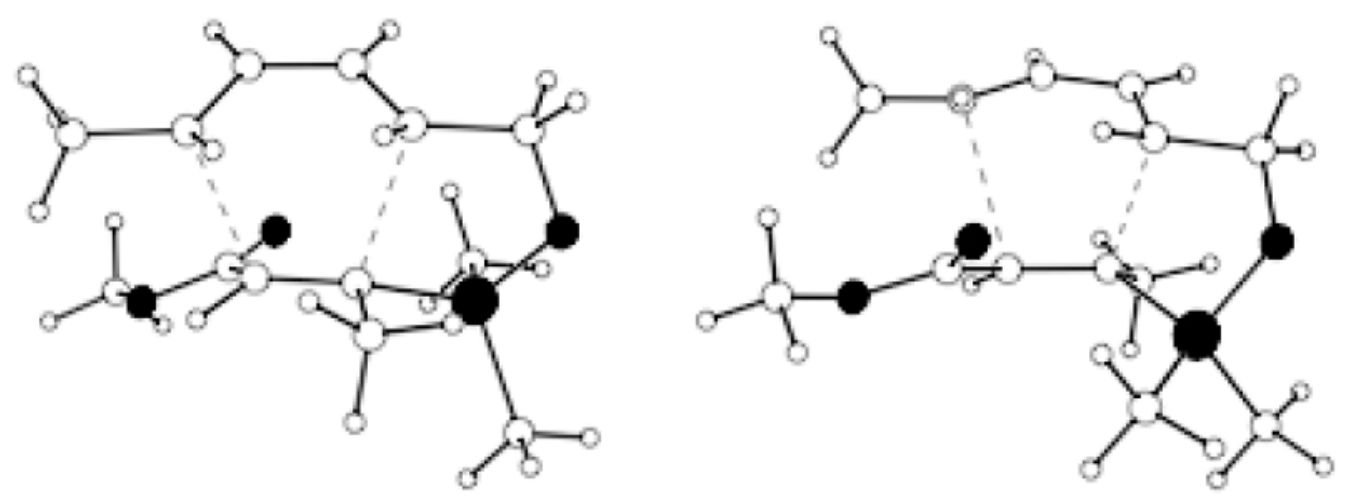

Figure 1.

Calculated transition state structures. 

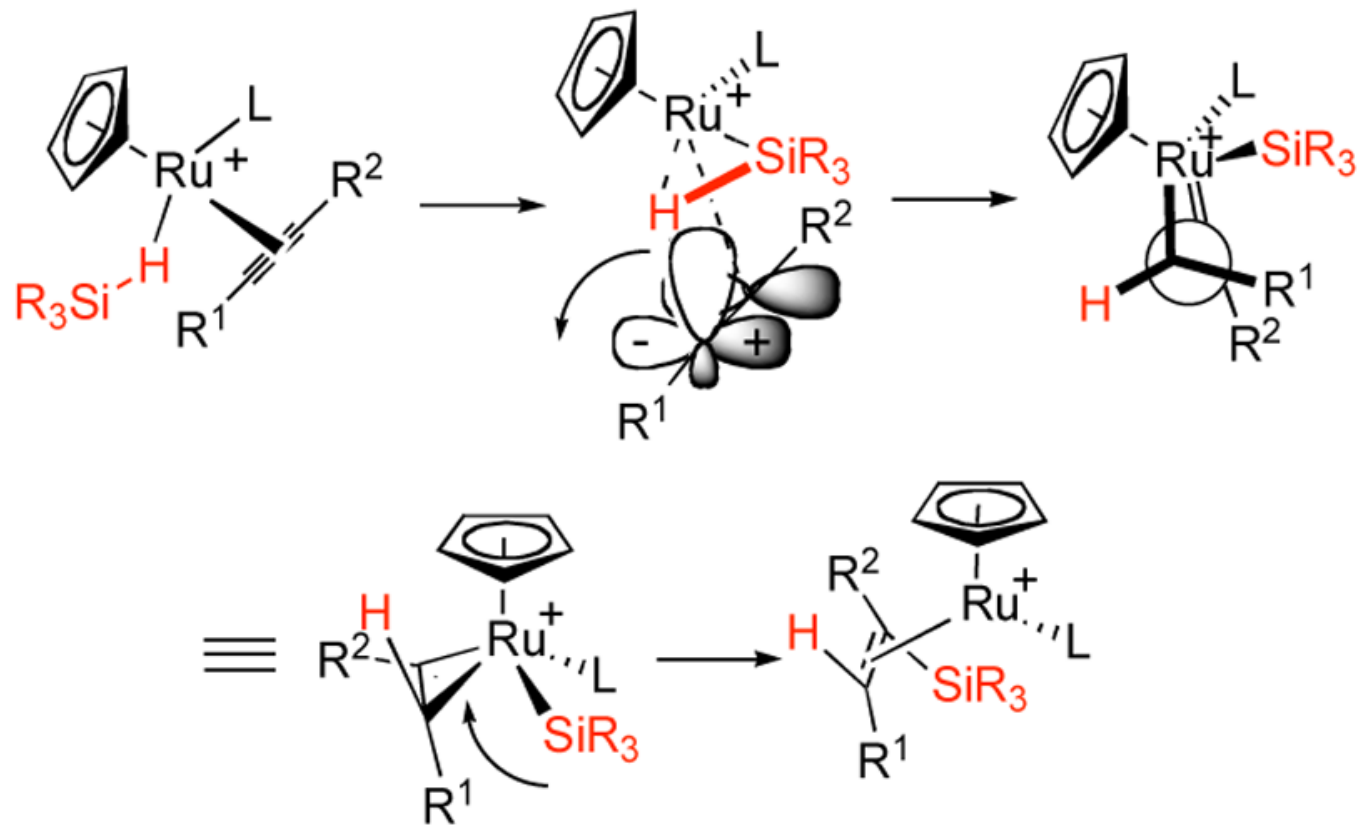

Figure 2.

A proposed mechanism for transition addition without cis-trans isomerization. 


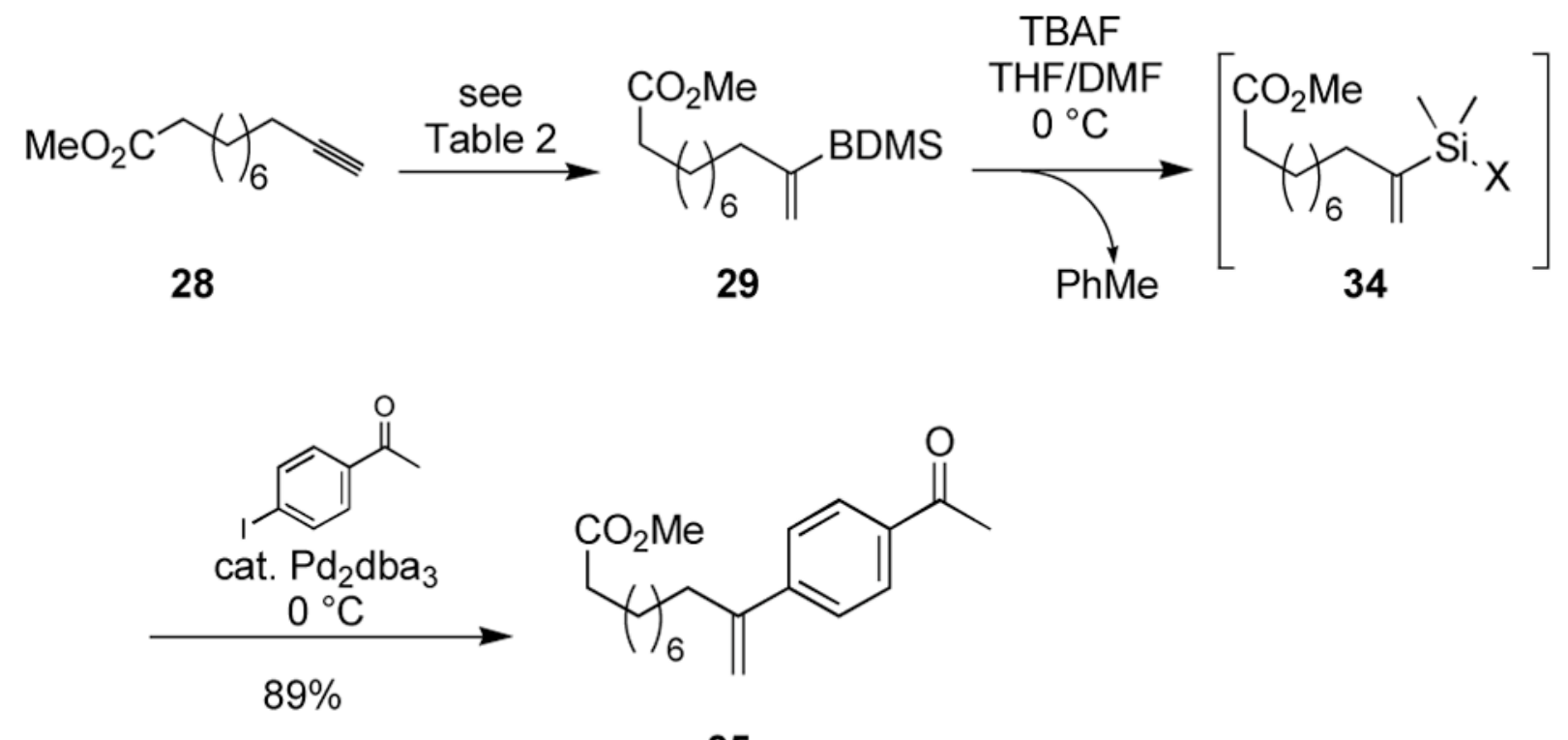

Scheme 1.

Synthetic utility of benzyldimethylsilanes. 


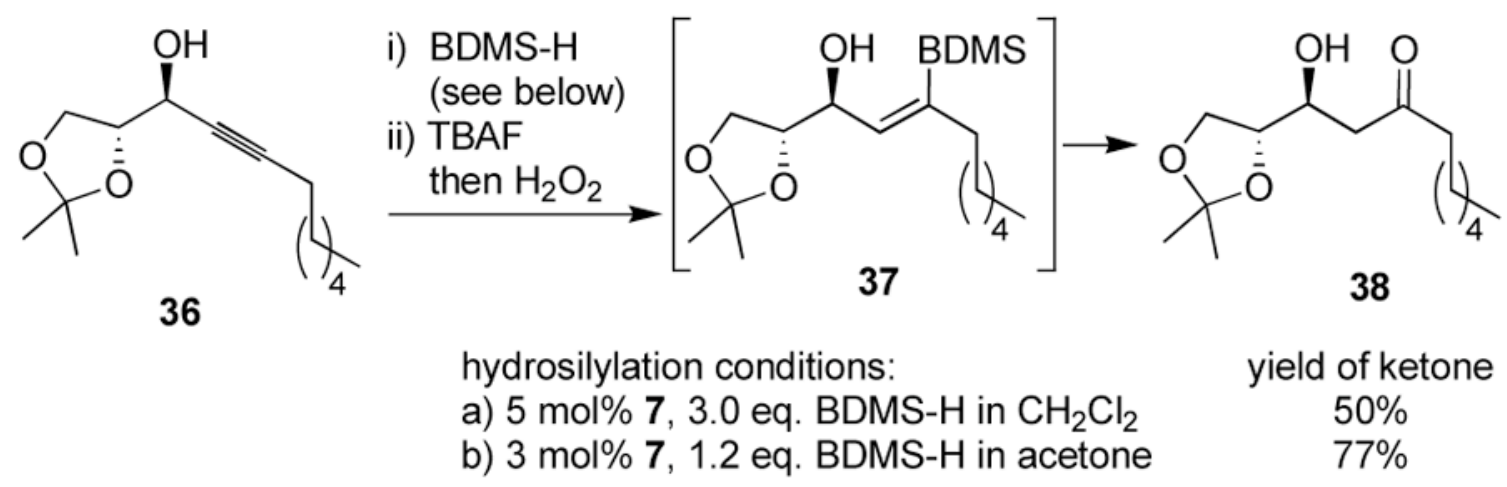

Scheme 2.

Solvent optimization. 

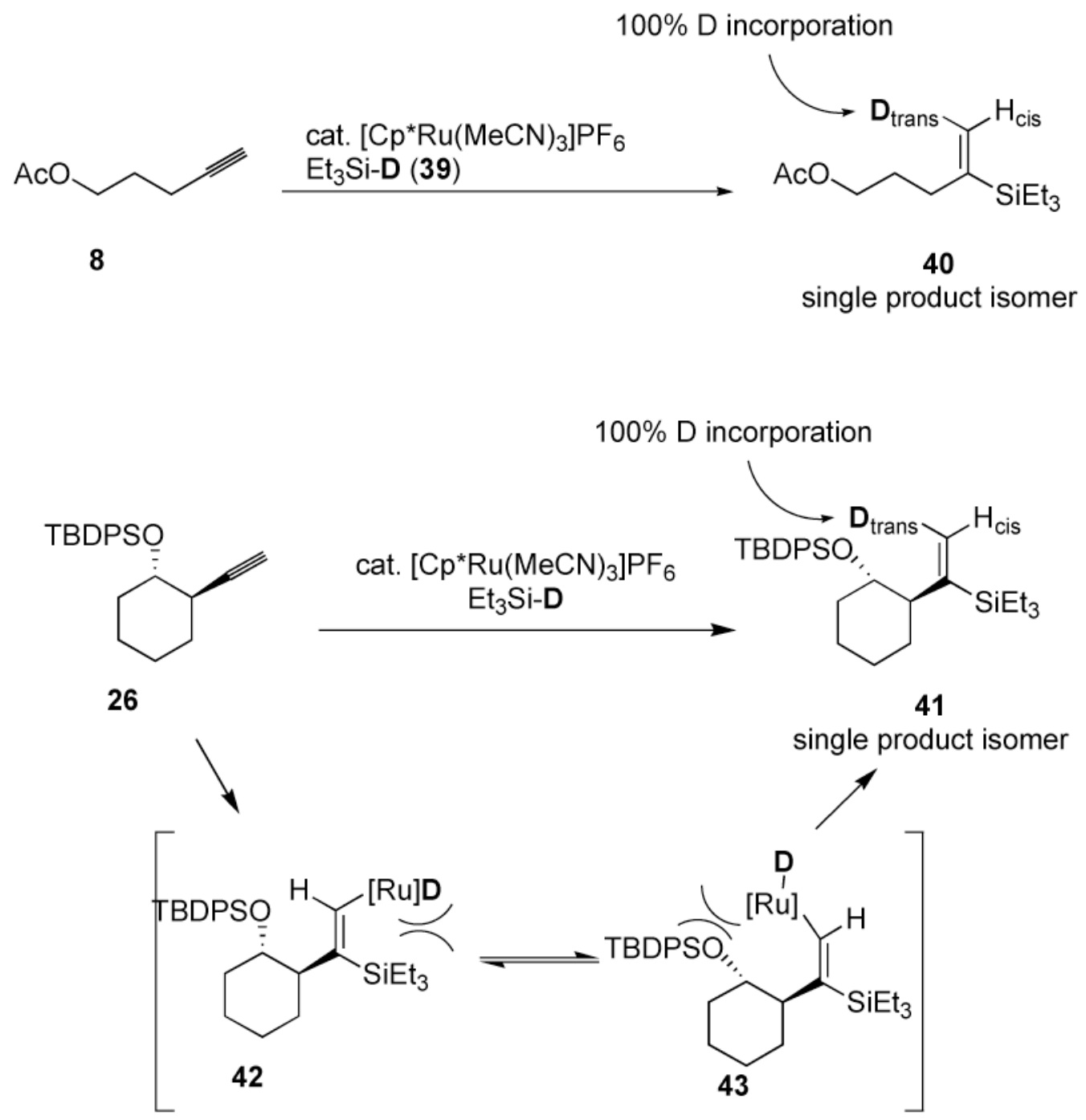

Scheme 3.

Deuterium labeling of terminal alkynes. 

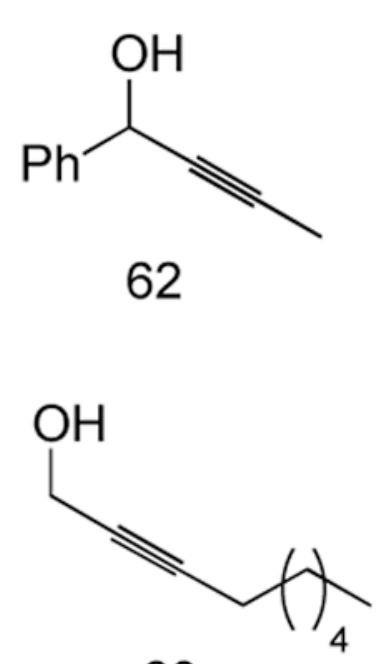

63
$(\mathrm{EtO})_{3} \mathrm{SiH}$

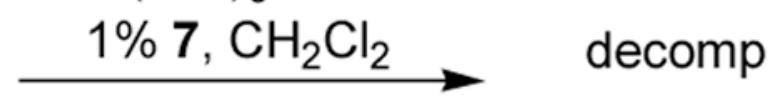

Scheme 4.

Failed attempts at propargylic alcohol hydrosilylation.

\section{$(\mathrm{EtO})_{3} \mathrm{SiH}$}

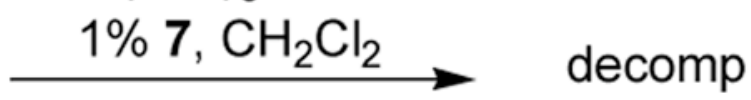




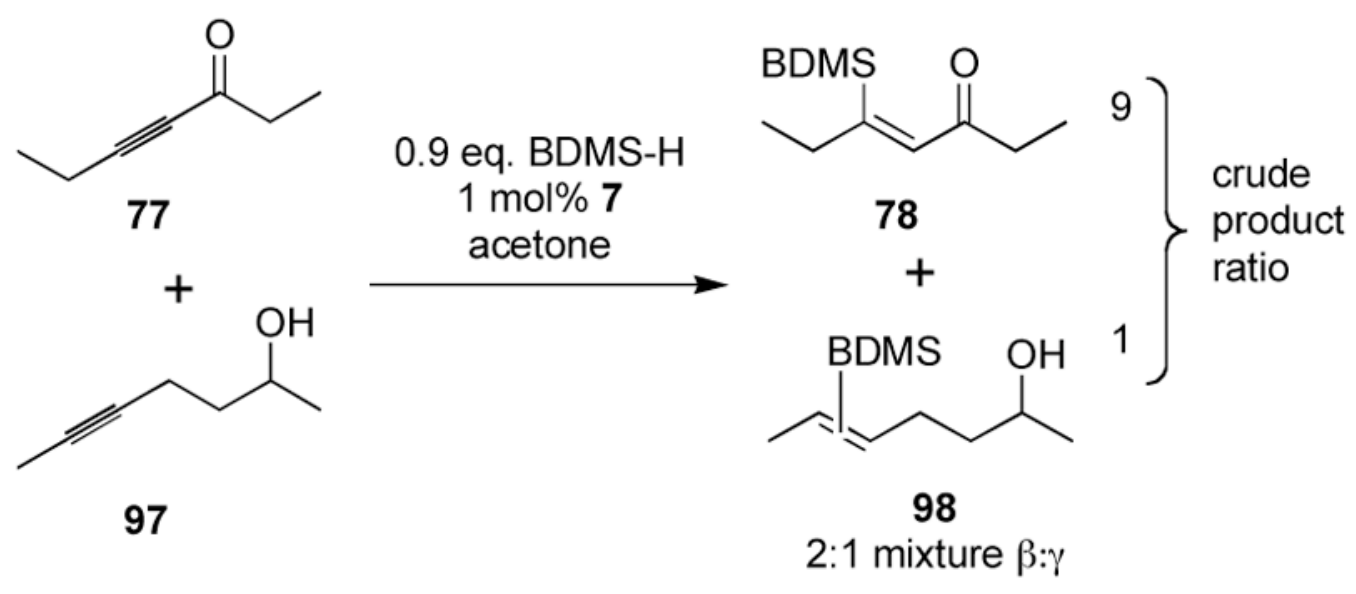

Scheme 5.

Chemoselectivity among alkynes. 


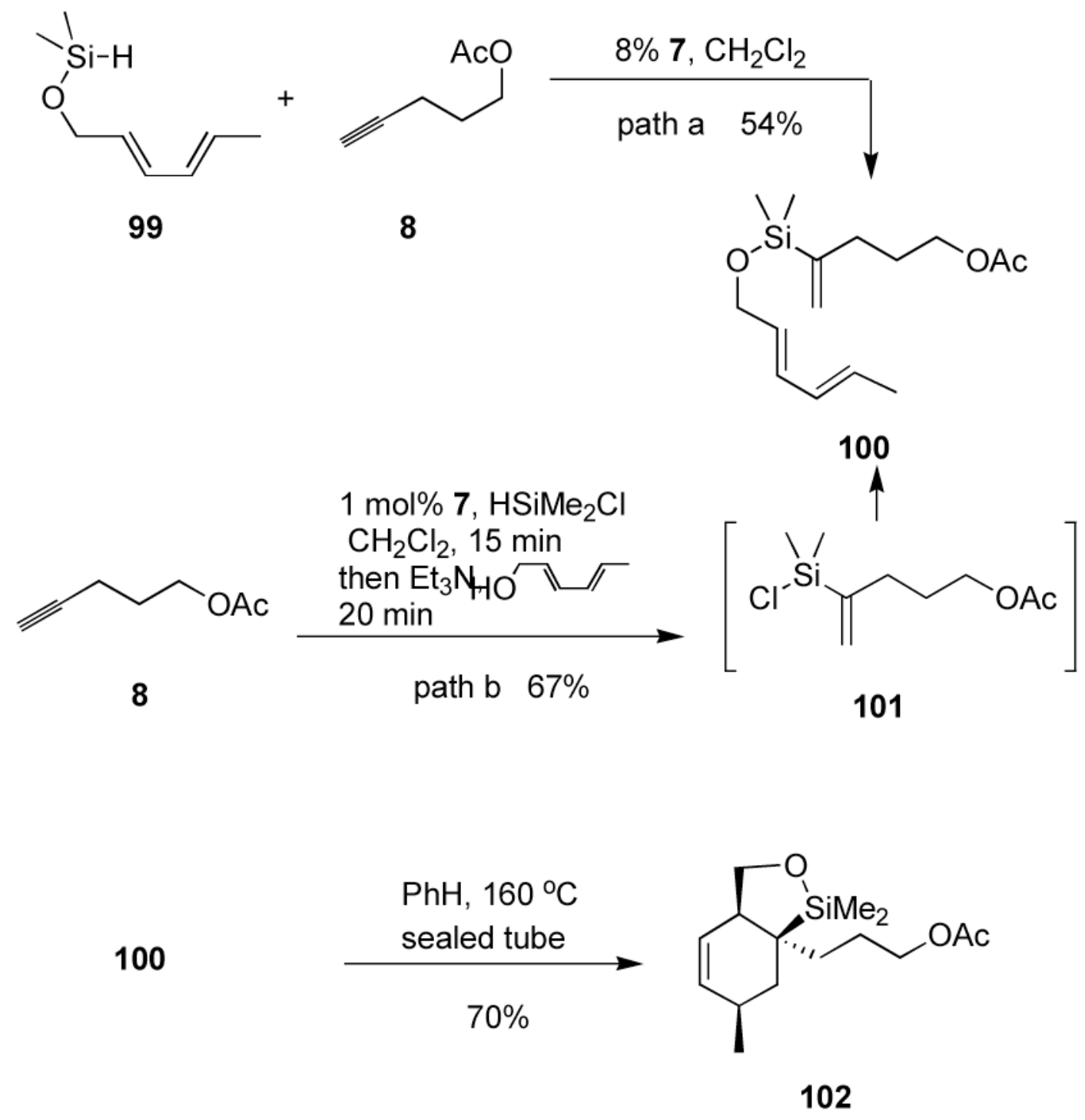

Scheme 6.

Synthesis of tethered Diels-Alder substrates with hydrosilylation. 

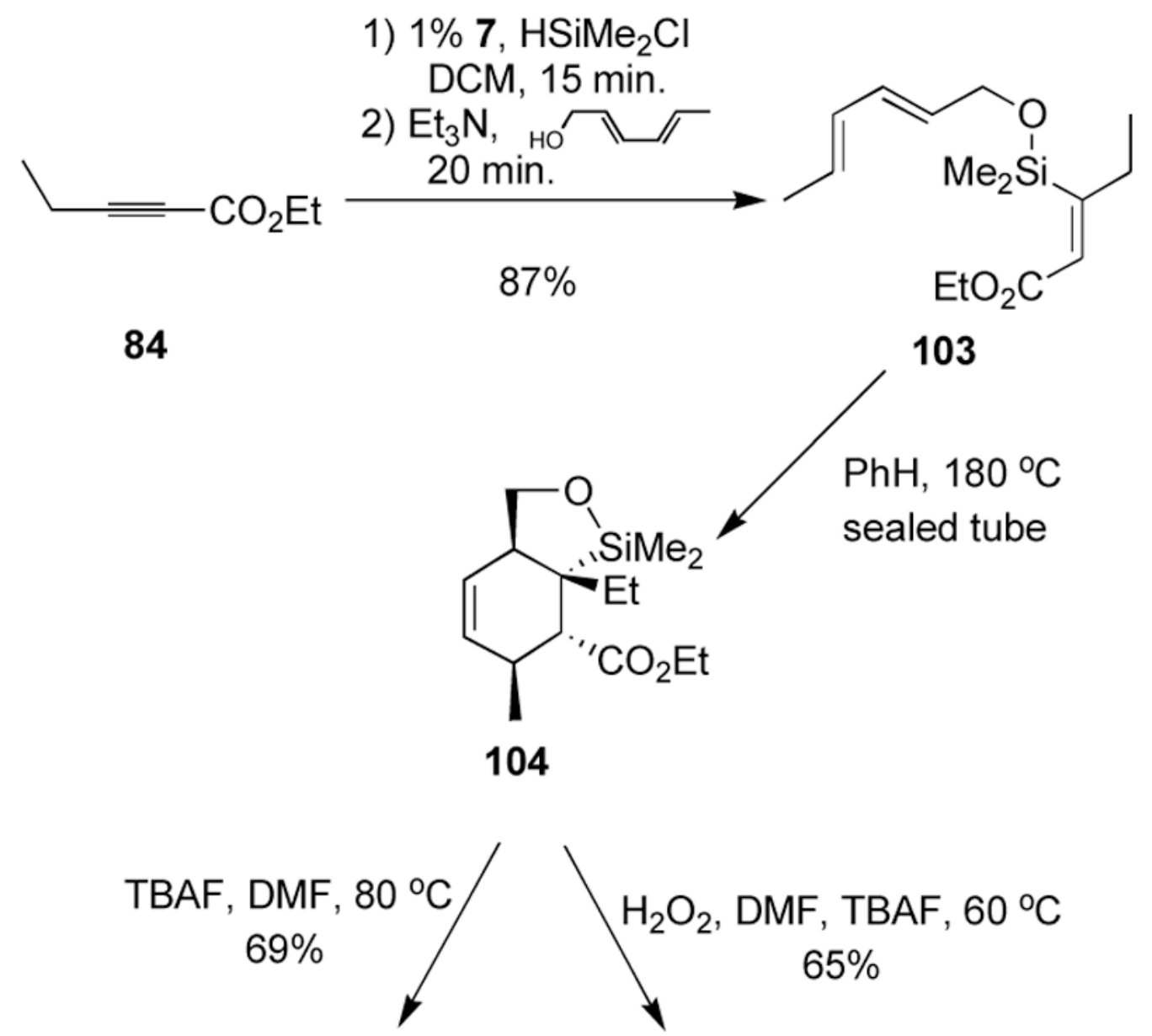

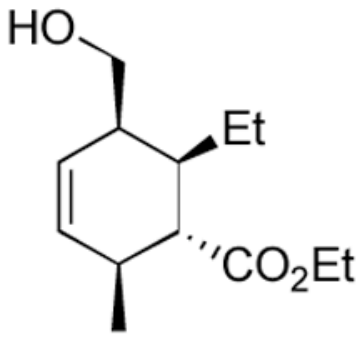

105

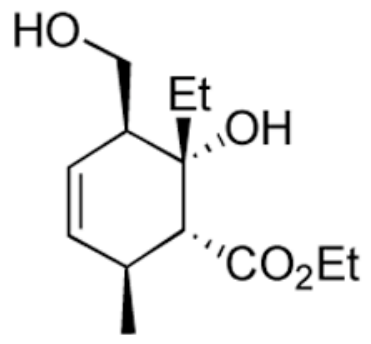

106

Scheme 7.

Alkyne hydrosilylation to build more complex substrates for silicon-tethered Diels-Alder reactions. 

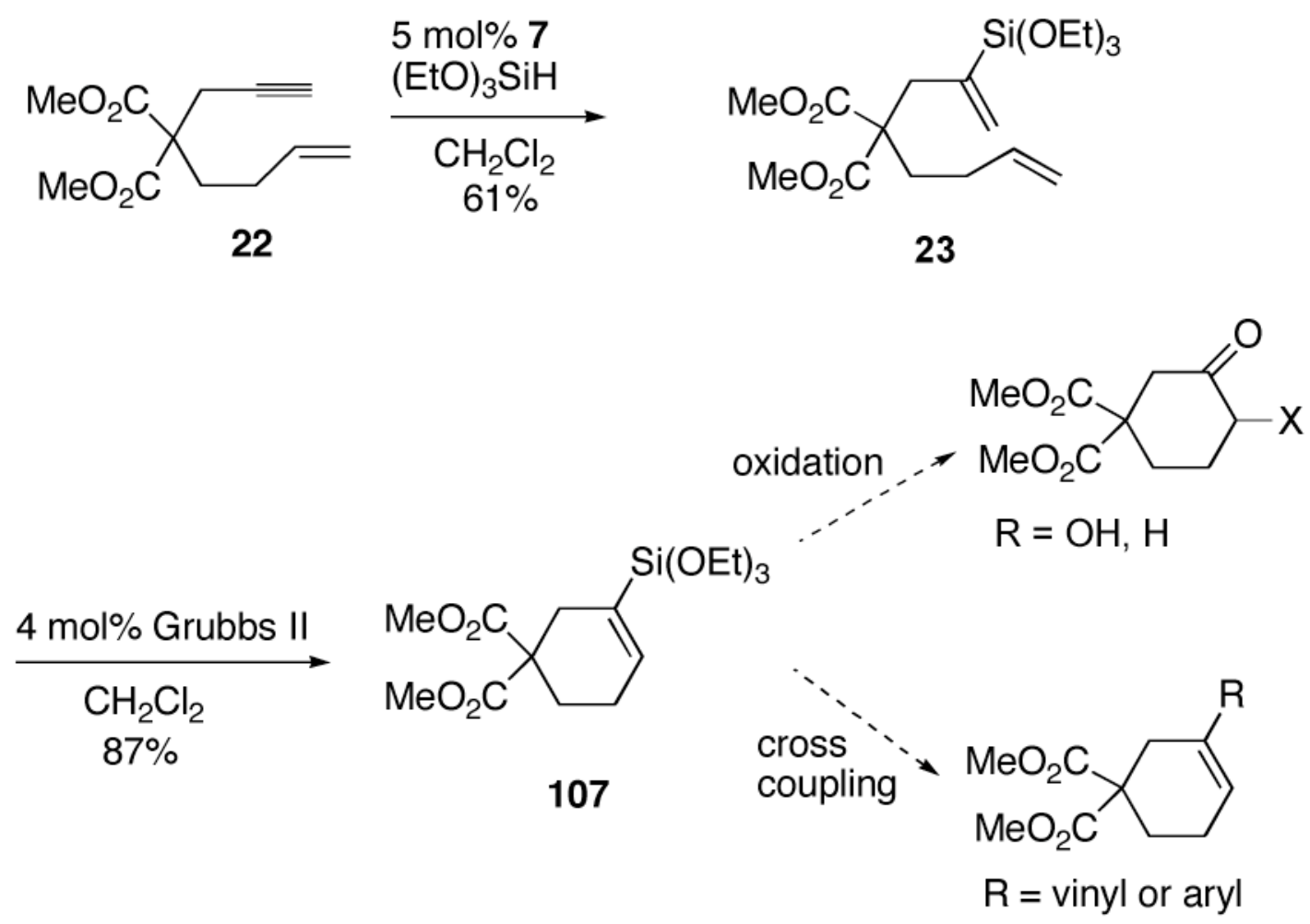

Scheme 8.

Hydrosilylation-metathesis for cyclic vinylsilane formation. 


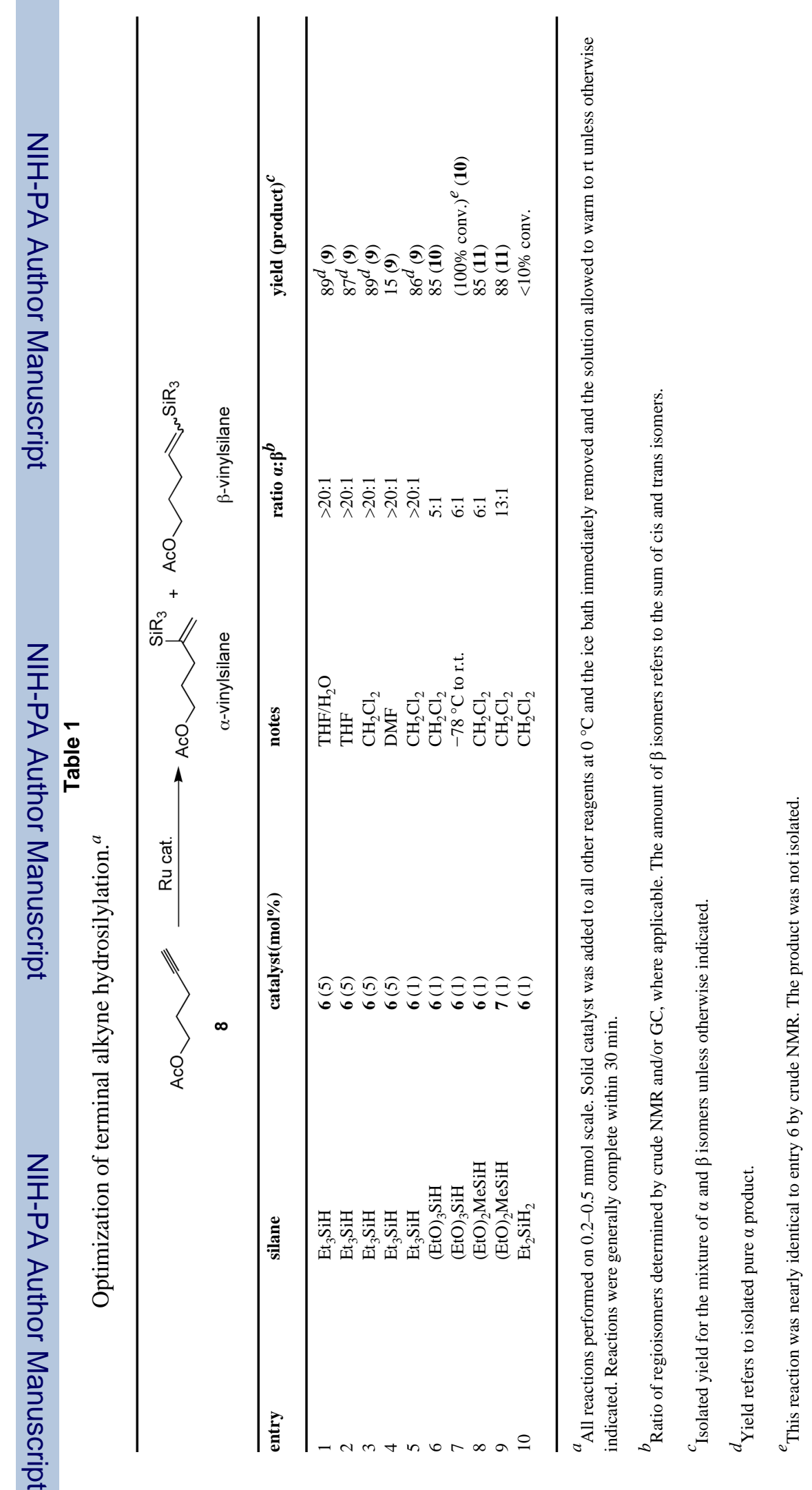




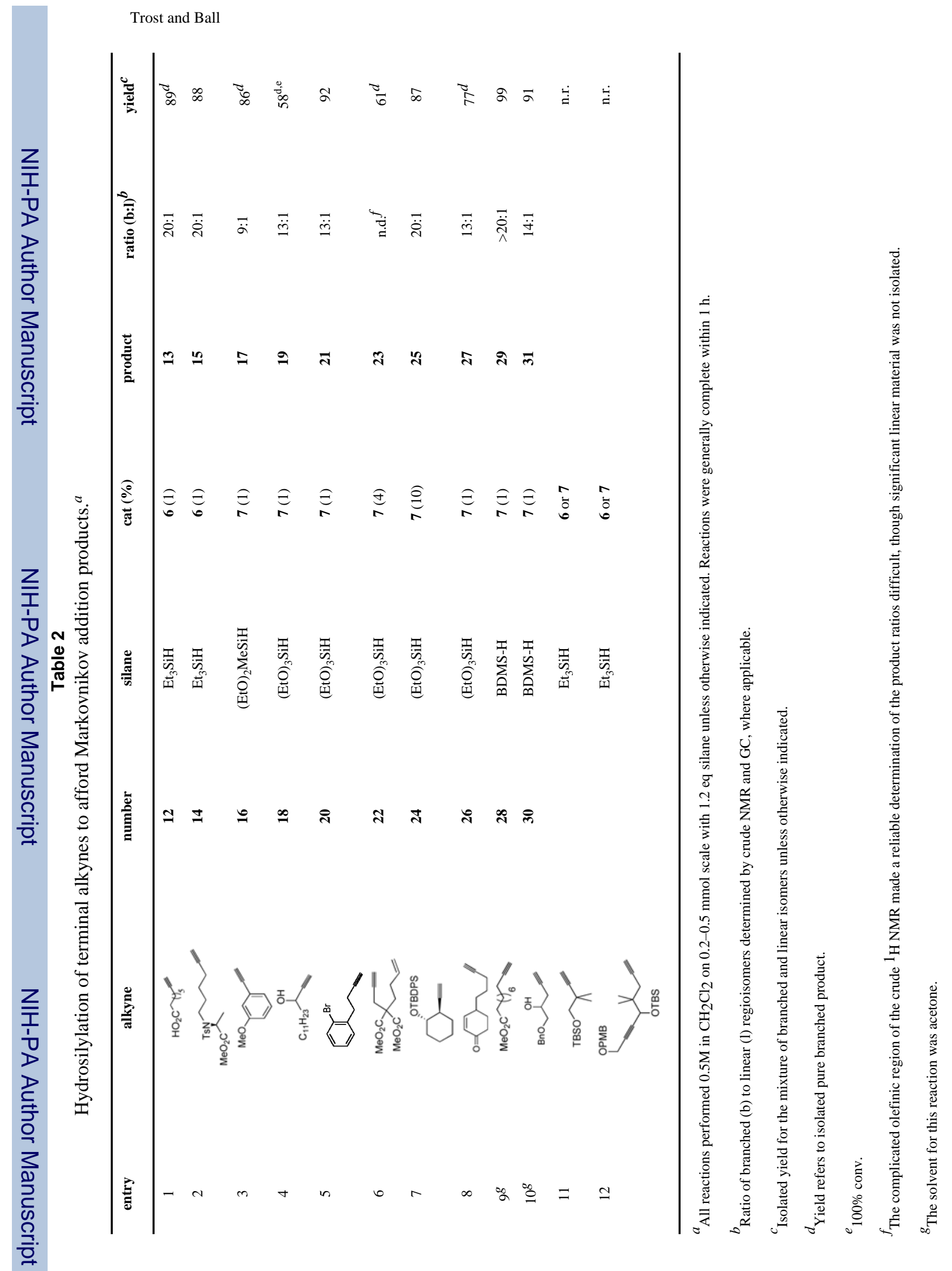

J Am Chem Soc. Author manuscript; available in PMC 2008 September 9. 


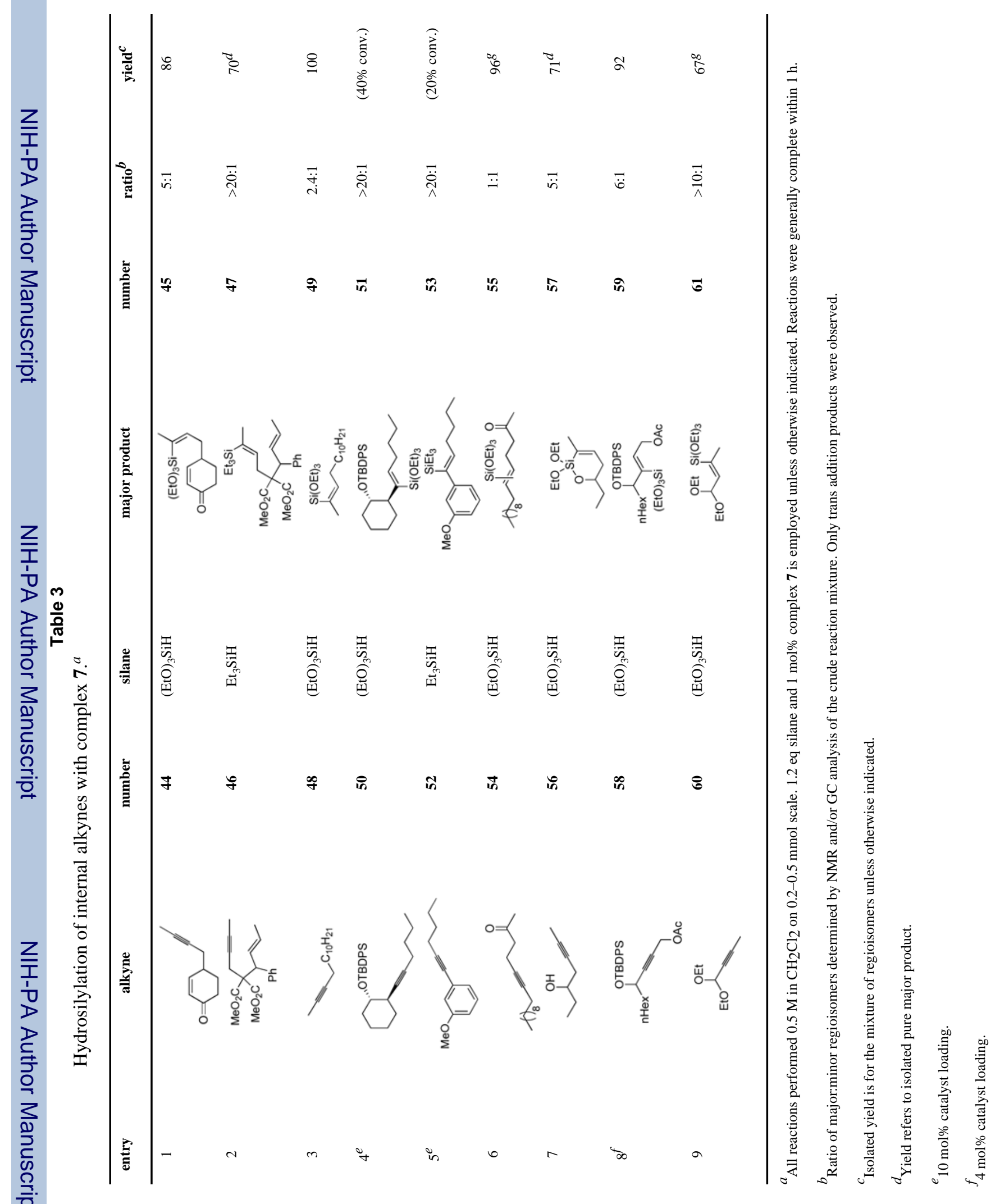




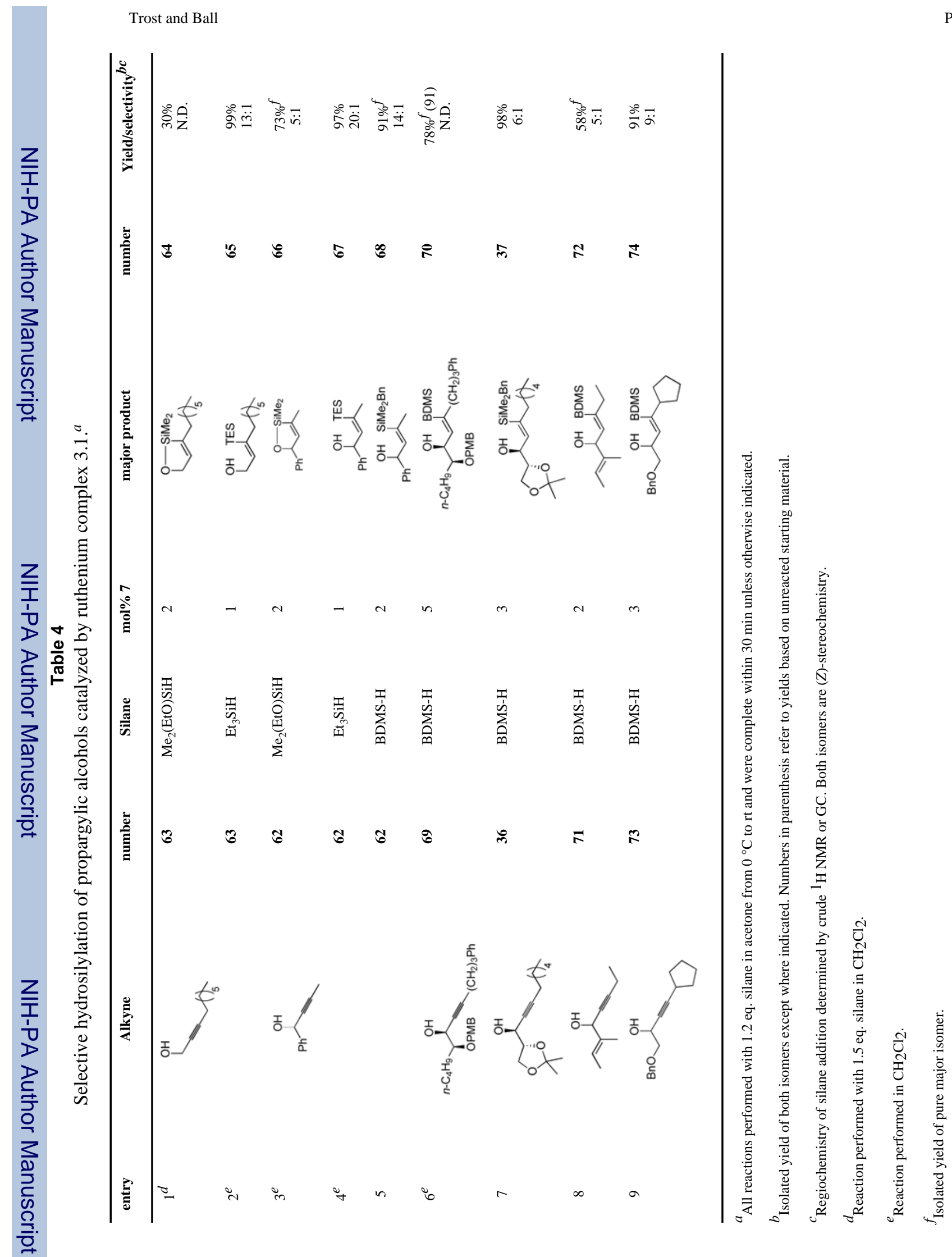

$J$ Am Chem Soc. Author manuscript; available in PMC 2008 September 9. 


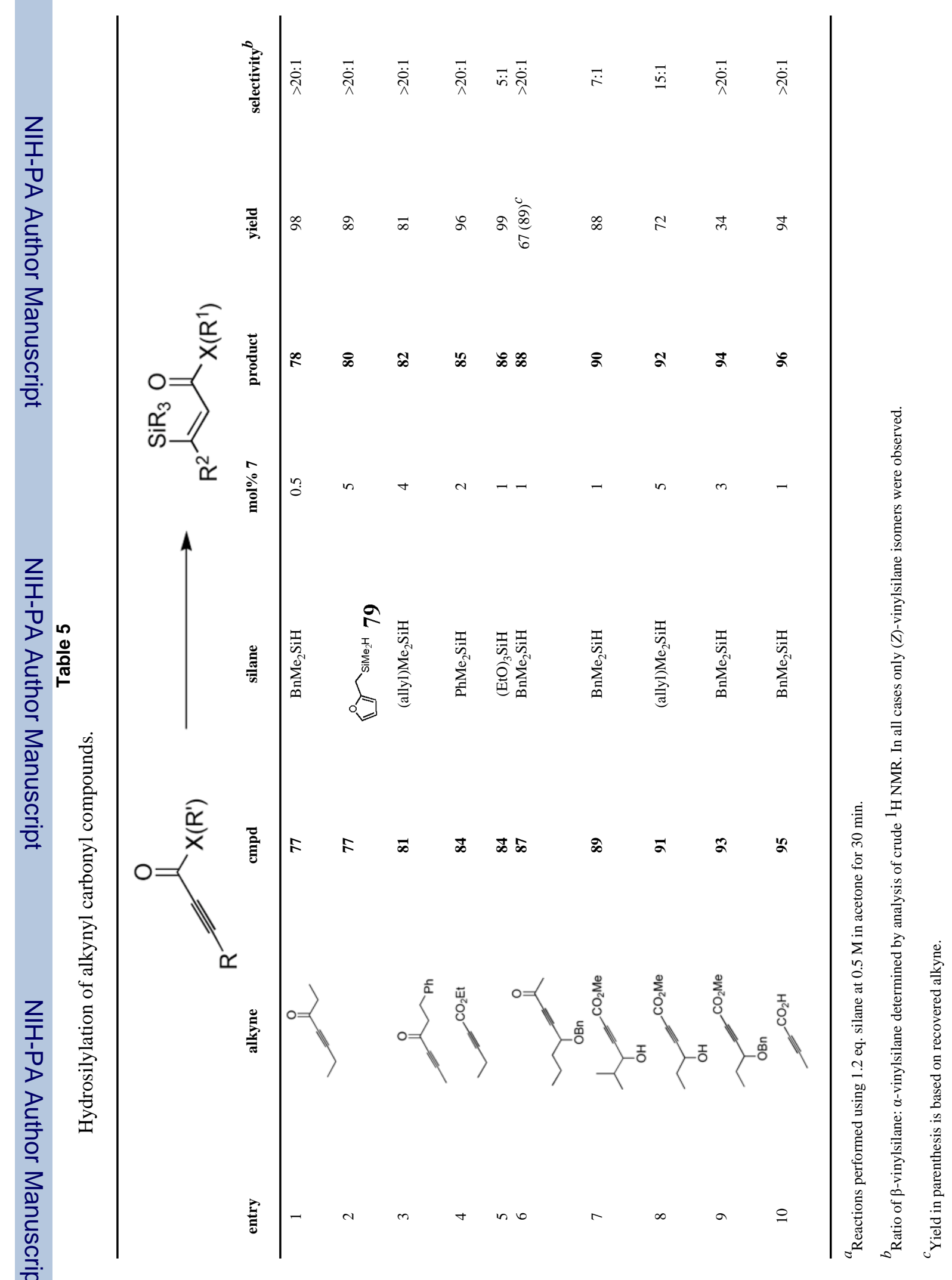

